\title{
$\begin{array}{ll}\text { Research Square } & \text { Preprints are preliminary reports that have not undergone peer review. } \\ \text { They should not be considered conclusive, used to inform clinical practice, }\end{array}$

\section{DNA damage in tissue-resident macrophages leads to age-related neurodegeneration}

George garinis ( $\square$ garinis@imbb.forth.gr )

IMBB-FORTH / University of Crete https://orcid.org/0000-0002-3200-5004

Katerina Gkirtzimanaki

IMBB-FORTH / University of Crete

\section{Edisona Tsakani}

IMBB-FORTH / University of Crete

Ermioni Arvanitaki

IMBB-FORTH / University of Crete

\section{Electra Nenedaki}

IMBB-FORTH / University of Crete

\section{Mary Kefalogianni}

Department of Physics, University of Crete

\section{Georgios Niotis}

IMBB-FORTH / University of Crete

Ilias Kalafatakis

IMBB-FORTH / University of Crete

Evi Goulielmaki

IMBB-FORTH / University of Crete

\section{Sotiris Psilodimitrakopoulos}

Department of Physics, University of Crete

\section{Domna Karagogeos}

IMBB-FORTH / University of Crete https://orcid.org/0000-0002-8129-9731

\section{Emmanuel Stratakis}

Foundation for Research and Technology Hellas https://orcid.org/0000-0002-1908-8618

\section{Article}

Keywords: DNA damage, ERCC1-XPF, neuroinflammation

Posted Date: December 1st, 2021

DOI: https://doi.org/10.21203/rs.3.rs-1059819/v1 
License: (c) (i) This work is licensed under a Creative Commons Attribution 4.0 International License. Read Full License 


\section{Abstract}

Neurodegenerative disorders are a growing challenge for the elderly yet their etiology remains elusive. Here, we show that persistent DNA damage in tissue-resident macrophages carrying an ERCC1-XPF DNA repair defect leads to cerebellar ataxia in mice. We find that cytoplasmic chromatin fragments accumulate in the brain microglia of progeroid and naturally aged mice stimulating a type-l Interferon (IFN-I) response and are then packaged in extracellular vesicles (EVs) leading to Purkinje cell death and neurodegeneration in $\mathrm{Er}^{\mathrm{CX} /-}$ animals. To reduce neuroinflammation, we developed an EV-based strategy to deliver recombinant DNase I specifically in inflamed $E r 7^{\mathrm{CX} /-}$ microglia in vivo. Our approach rapidly removes dsDNAs from the cytoplasm of microglial cells and in secreted EVs; it alleviates the IFN-I response, decreases Purkinje cell death and delays the onset of neuronal decline in $\mathrm{Er}^{\mathrm{CX} /-}$ animals. Thus, brain microglia causally contribute to neurodegeneration allowing for the development of promising therapeutic strategies against age-related neuroinflammation.

\section{Introduction}

To counteract DNA damage, cells rely on a series of partially overlapping DNA repair pathways to preserve their vital genetic information and faithfully transmit it to progeny ${ }^{1}$. Besides cancer, the great majority of DNA repair defects in man gives rise to a heterogeneous group of progeroid (premature aginglike) syndromes that present frequently or exclusively with mild to severe neurological symptoms ${ }^{2}$. Indeed, in view of the DNA repair defect, the high oxidative load and metabolic by-products generated during normal brain metabolism are thought to trigger irreparable DNA modifications driving neuronal cell death and the progressive degeneration of the central or peripheral nervous systems ${ }^{3}$.

Xeroderma Pigmentosum F-Excision Repair Cross Complementation group 1 (XPF-ERCC1) is a heterodimeric, structure-specific endonuclease complex required for lesion excision in nucleotide excision repair (NER) ${ }^{4,5}$ that plays an analogous role in the repair of highly cytotoxic DNA interstrand crosslinks (ICLs) ${ }^{6}$. Patients with mutations in XPF may present with mild symptoms of the NER-deficient syndrome $\mathrm{XP}$ or exhibit adult-onset progressive neurologic deterioration, including chorea, ataxia, cognitive deficits and brain atrophy ${ }^{7}$. Recently, a single patient was discovered with mutations in ERCC1 resulting in severe pre- and postnatal developmental defects as well as pronounced neurological alterations associated with cerebellar hypoplasia and blunted cortical gyri 8,9

We and others have recently shown that DNA damage-driven inflammation causally contributes to agerelated, tissue degenerative changes ${ }^{10-13}$. However, the relative contribution of compromised genome integrity in distinct cell types, e.g. neurons or glial cells to age-related neurodegenerative features remains unknown. Using Er7 ${ }^{\mathrm{CX} /-}$ mice with an engineered ERCC1-XPF defect only in tissue-resident macrophages, we provide evidence for a fundamental mechanism by which irreparable DNA damage leads to the accumulation of chromatin fragments in the cytoplasm of microglial cells. Using functional assays coupled to an advanced simultaneous 2-3 multiphoton analysis on acute brain slices, we find that 
cytoplasmic chromatin fragments are sensed, stimulating a type-I IFN response. We find that cytoplasmic chromatin fragments are packaged in microglia-derived $E r 7^{\mathrm{CX} /-} \mathrm{EV}$ s that selectively target Purkinje cells leading to their apoptotic death and the premature onset of neurodegeneration in $\mathrm{Er} 7^{\mathrm{CX} /-}$ animals. To remove cytoplasmic dsDNAs from the cytoplasm of activated microglial cells and lessen the neuroinflammatory load in $\mathrm{Er}^{\mathrm{CX} /{ }^{-}}$mice, we developed an extracellular vesicle (EV)-based strategy to deliver recombinant DNase 1 nuclease in vitro and in vivo, targeting CD $11 \mathrm{~b}^{+}$cells of the brain. We find that treatment with the EV-delivered nuclease cargo rapidly eliminates inflammatory dsDNA moieties from the cytoplasm of microglia cells and in microglia-secreted EVs. This approach alleviates the Type-I IFN response and Purkinje cell death, leading to the substantial delay in the premature onset of cerebellar ataxia in $\mathrm{Er}^{\mathrm{CX} /-}$ animals. Taken together, our findings highlight the prominent role of tissue-resident macrophages in age-related neurodegeneration opening new avenues for the development of novel intervention strategies against neuroinflammatory disorders.

\section{Results}

Loss of ERCC1 in tissue-resident macrophages triggers progressive ataxia in mice. How DNA damage leads to the premature onset of heterogeneous pathological features in NER patients and accompanied animal models remains an intriguing question arguing for cell type-specific responses against genotoxic threats. Tissue-resident macrophages are a heterogeneous group of immune cells that reside in distinct tissue environments and are vital for tissue homeostasis and defense against foreign pathogens or environmental challenges ${ }^{14}$. To dissect the impact of irreparable DNA damage in tissue-resident macrophages, we intercrossed animals homozygous for the floxed $E r c c 1$ allele $\left(E r C C 1^{F / F}\right)$ with mice carrying the CX3CR1-Cre transgene in an Ercc1 heterozygous background (from now on denoted as $\mathrm{Er}^{\mathrm{CX} /-}$ animals). CX3CR1 is a $\mathrm{CX} 3 \mathrm{C}$ chemokine receptor 1 for fate-mapping studies of the tissue-resident monocyte and macrophage compartment ${ }^{15}$. Confocal microscopy studies in $\mathrm{CX} 3 \mathrm{Cr} 1$-Cre crossed with the Rosa YFP transgenic animals and in $E r 1^{\mathrm{CX} /-}$ animals confirmed the $\mathrm{Cx} 3 \mathrm{Cr} 1$-driven YFP expression (Figure $1 \mathrm{~A}$ ) and the absence of ERCC1 expression in $\mathrm{Er}^{\mathrm{CX} /-}$ tissue-resident macrophages, respectively (Figure 1B). Together, these findings indicate the normative ERCC1 expression levels in $\mathrm{Er}^{\mathrm{CX} /-}$ tissues or cells other than the targeted cell population. $E r 7^{\mathrm{Cx} /-}$ mice are born at the expected Mendelian frequency and present no developmental defects or other pathological features. At 4-months of age, however, $E r 1^{\mathrm{Cx} /}$ - mice manifest progressively signs of ataxia that become clearly evident in the 6-months old animals. In line, when the 6-months old wild-type mice ( $E r 7^{F /-}$; wt.) are suspended by their tails, the animals extend and shake their hind limbs to maintain balance (Supplementary Video file 1). Instead, $E r 7^{\mathrm{Cx} /-}$ mice keep their hind limbs in a clasped position (Figure 1C; Supplementary Video file 2) and walk with a wide gait compared to age-matched littermate control animals. Rotarod assessment reveals that hind limb coordination deficiency is apparent in $\sim 70 \%$ of the 6-months old $\mathrm{Er}^{\mathrm{Cx} /-}$ animals compared to $\mathrm{Er} 7^{\mathrm{F} /-}$ littermate controls (Figure 1D). Beginning at 8-months of age, $\mathrm{Er}^{\mathrm{Cx} /-}$ animals develop kyphosis (Figure $1 \mathrm{E})$ and fine tremor to front legs. The premature onset of neurodegenerative features in $\mathrm{Er} 7^{\mathrm{Cx} /-}$ animals prompted us to assess the morphological and phenotypic characteristics of CNS-resident macrophages. 
We find that brain microglia in 6-months old $\mathrm{Er} 7^{\mathrm{Cx} /-}$ animals form finger-like protrusions, a hallmark of microglia activation that involves cellular locomotion and increased antigen presentation ${ }^{16}$ (Figure 1F). Fluorescence-activated cell sorting (FACS) analysis of freshly isolated CD11 ${ }^{+}$cells derived from Er7 $7^{\mathrm{Cx} /-}$ brains revealed a substantial increase in cell size (Figure 1G), in the expression of MHCII and CD86 proteins as well as the number of $\mathrm{MHClI}^{+} \mathrm{CD}^{2} 6^{+}$cells compared to $\mathrm{CD} 11 \mathrm{~b}^{+}$cells of $\mathrm{Er} \mathrm{F}^{\mathrm{F}-}$ animals (Figure $1 \mathrm{H}$ and). However, when compared to LPS-treated, fully activated pro-inflammatory microglia, Er1 ${ }^{\mathrm{Cx} /-}$ microglia appear to be in a primed, yet not fully activated sate (Figure $1 \mathrm{H}$ and Supplementary Figure $\mathrm{S} 1 \mathrm{~A})$. Further work reveals a comparable number of microglial cells in the 3 - and 6-months old $\mathrm{Er} 7^{\mathrm{Cx} /-}$ and $E r 7^{F /-}$ brains (Figure 11). The lack of infiltrating monocytes as assessed by the histological evaluation of 3- and 6-months old $E r 1^{\mathrm{Cx} /-}$ brains (Figure $1 \mathrm{~J}$ ), the normative $\mathrm{CD} 45$ expression levels in the 6-months old $\mathrm{Er}^{\mathrm{Cx} /-}$ brains (Figure $1 \mathrm{~J}$; Supplementary Figure S1B) and the comparable number of Ly6 $\mathrm{C}^{+}$ bone marrow-derived macrophages in the 6-months old $\mathrm{Er}^{\mathrm{Cx} /-}$ and $\mathrm{Er}^{\mathrm{F/} /-}$ brains (Figure $1 \mathrm{~K}$ ) diminishes the possibility of peripheral immune cell infiltration in $\mathrm{Er}^{\mathrm{Cx} /-}$ brains.

\section{Accumulation of cytoplasmic chromatin fragments triggers a type-I IFN response in $\mathrm{Er} 1^{\mathrm{Cx} /-}$ microglia.}

Phosphorylated histone H2A.X ( $\gamma$-H2A.X)-containing foci accumulate at sites of DNA breaks ${ }^{17}$. FACS analysis in single cell suspensions of $E r 7^{F /+}$ brains reveal that the great majority of $\gamma$-H2A.X. $X^{+}$cells are CD11 $\mathrm{b}^{+} \mathrm{NeuN}$ - cells (Figure 2A; upper panel). Intriguingly, we find that the percentage of $\gamma^{-}$ $\mathrm{H} 2 \mathrm{~A} . \mathrm{X}^{+} \mathrm{CD} 11 \mathrm{~b}^{+} \mathrm{NeuN}^{-}$cells increases gradually from 3- to 12-months old $\mathrm{Er} \mathrm{T}^{\mathrm{F} /+}$ brains indicating that microglia cells accumulate rapidly DNA damage compared to neuronal cell types with aging. Consistent with the DNA repair defect, we find a significantly higher percentage of $\gamma-\mathrm{H} 2 \mathrm{~A} . \mathrm{X}^{+} \mathrm{CD} 11 \mathrm{~b}^{+} \mathrm{NeuN}{ }^{-}$cells in $\mathrm{Er}^{\mathrm{CX} /-}$ brains compared to littermate controls across all age groups (Figure 2A; lower panel). The phosphorylated Ataxia telangiectasia-mutated protein (pATM) is a central mediator of the DNA damage response. Confocal microscopy studies confirmed the significant increase in the number of $y$-H2A.X+ $\mathrm{CD} 11 \mathrm{~b}+$ and pATM+CD11b+ cells in $\mathrm{Er} \mathrm{T}^{\mathrm{Cx} /-}$ brains compared to $\mathrm{Er}^{\mathrm{Fl} /}$ controls (Figure 2B; as indicated). Interestingly, $y-\mathrm{H} 2 \mathrm{AX}$ and pATM accumulate in the nucleus as well as the cytoplasm of microglial cells in $\mathrm{Er}^{\mathrm{Cx} /-}$ brains. Unlike in $\mathrm{Er}^{\mathrm{F} /-}$ microglia cells, we also detect the presence of 4',6-diamidino-2phenylindole (DAPI) dense foci marking the presence of chromatin in the cytoplasm of $\mathrm{Er}^{\mathrm{Cx} /-}$ freshly isolated microglial cells (Figure 2C). DNA damage triggers the release of micronuclei containing whole or fragmented chromosomes into the cytoplasm ${ }^{18}$. Chromatin fragments are subject to autophagic degradation ${ }^{19}$ or else accumulate stimulating a type-I IFN immune response ${ }^{20}$. The presence of chromatin fragments in the cytoplasm of cells prompts us to test whether nuclear DNA leakage in the cytoplasm of $\mathrm{Er} 7^{\mathrm{Cx} /-}$ microglia cells triggers the activation of a type-I IFN response, known to be associated with anti-viral and immune modulating functions ${ }^{21}$. Evaluation of the bioactive murine type-I IFN levels by means of the B16-Blue ${ }^{T M}$ IFN- $\alpha / \beta$ cell line in the extracellular milieu (brain lavage) of the 6months old $E r 7^{\mathrm{CX} /-}$ and aged-matched $E r 7^{\mathrm{F} /-}$ littermate control animals reveals significantly higher type-I IFN levels in $\mathrm{Er}^{\mathrm{Cx} /-}$ brains (Figure 3A). Consistently, we find an increase in the mRNA levels of several interferon signature genes (ISGs) i.e. ifn $\beta$, ifit2, ifi207 and ifi 44 in $\mathrm{Er}^{\mathrm{CX} /-}$ whole brain lysates (Figure 3B). 
FACS analysis in the 6-months old $E r 7^{\mathrm{Cx} /-}$ cerebella and cortices reveal an increase in pSTING (phosphorylated form of stimulator of interferon genes) protein levels known to act as a sensor of cyclic d-GMP and as an adaptor protein mediating the interferon response, once activated by DNA sensors like cGAS (Figure $3 \mathrm{C})^{22}$. In $\mathrm{Er}^{\mathrm{Cx} /-}$ microglial cells, we find that cytoplasmic DAPI+ chromatin colocalizes with the autophagy protein LC3 $\beta$ known to be involved in membrane trafficking and substrate delivery to lysosomes ${ }^{23}$ and lamin B1, a nuclear lamina protein associated with chromatin domains ${ }^{24}$ that is markedly disorganized in $\mathrm{Er}^{\mathrm{Cx} /-}$ microglial cells compared to controls (Figure 3D; as indicated and Supplementary Figure S2A). Consistently, we find that $\mathrm{pATM}^{+} \mathrm{DAPI}^{+}$chromatin structures accumulate in the cytoplasm of $\mathrm{Er}^{\mathrm{CX} /-}$ cells and are surrounded by P62, a sequestering protein that delivers substrates to forming autophagosomes ${ }^{25}$ (Figure 3E; as indicated and Supplementary Figure S2B). Together, these findings indicate a physiological budding response of $\mathrm{Er}^{\mathrm{CX} /{ }^{-}}$microglial cells to remove irreversibly damaged chromatin fragments through nucleophagy. We recently showed that type-I IFN mediates the increase of lysosomal $\mathrm{pH}$ to delay autophagosomal degradation, thereby favoring antigen presentation and cytokine secretion ${ }^{26}$. In agreement, we find that the lysosomal $\mathrm{pH}$ of freshly isolated $\mathrm{CD} 11 \mathrm{~b}^{+}$cells is significantly increased indicating that lysosomal acidity is compromised in $\mathrm{Er}^{\mathrm{C}} \mathrm{Cx} /{ }^{-}$brain-derived microglia cells (Figure 3F). The latter may well explain the pronounced accumulation of chromatin fragments in the cytoplasm of DNA repair-deficient $\mathrm{Er}^{\mathrm{CX} /{ }^{-}}$microglial cells. Next, we test whether cytoplasmic chromatin fragments also accumulate with natural aging. In line, we find that DAPI-stained chromatin fragments accumulate in the cytoplasm of microglial cells derived from 24-months old naturally aged mice cells (Figure $3 G$ ). Similar to 6-months old $E r 7^{\mathrm{Cx} /-}$ animals, FACS analysis revealed an increase in pSTING protein levels in naturally aged cerebella (Figure $3 \mathrm{H}$ and Supplementary Figure S2C).

$\mathrm{Er} 1^{\mathrm{Cx} / \text { - }}$ microglia elicit antiviral-like response that triggers Purkinje neuronal cell death. A number of animal models carrying inborn defects in DDR (e.g. $\mathrm{Atm}^{-/}$) and genome maintenance (e.g. Csb ${ }^{m / m_{-}} \mathrm{Xpa}^{-/}$ ${ }^{-}$) develop cerebellar ataxia associated with Purkinje cell death ${ }^{27,28}$. However, unlike in DNA repairdeficient animal models, Purkinje cells in $E r 1^{\mathrm{Cx} /-}$ mice are DNA repair-proficient and do not accumulate $\mathrm{Y}^{-}$ H2AX foci in their nuclei (Figure 4A). Nonetheless, TUNEL assay and staining for activated Caspase-3 in 3- and 6-months old $E r^{\mathrm{Cx} /-}$ brain sections reveal increased cell death in the Purkinje cell layer of cerebellum (Figure 4B; as indicated). Loss of Purkinje cells is also in line with the defective coordination of hind limbs and the fine tremor seen in $\mathrm{Er}^{\mathrm{Cx} /-}$ animals (Figure $1 \mathrm{C}-\mathrm{D}$ ). Further work reveals that myelination is unaffected in the 6-months old $E r 7^{\mathrm{Cx} /-}$ mice as assessed by confocal microscopy of fluoromyelin and western blotting of MBP1 protein levels (Supplementary Figure S3A-B). FACS analysis of freshly isolated brain single cell suspensions using antibodies against Calbindin (for Purkinje cells), $\mathrm{CD}_{11 \mathrm{~b}^{+}}$(for microglia), Annexin $\mathrm{V}$ (for apoptosis) and Propidium lodide (for cell viability) reveals cell death in $\sim 30 \%$ of Purkinje cells in the 6 -months old $E r 7^{\mathrm{Cx} /-}$ brains (Figure $4 \mathrm{D}$ ). Instead, we find that $E r 7^{\mathrm{Cx} /}$ - microglia show no difference in Annexin $\mathrm{V}$ or Propidium lodide indicating that $E r 7^{\mathrm{Cx} /-}$ brain microglia is tolerant to DNA damage (Figure 4D and Supplementary Figure S4A). We previously showed that type-I IFNs and their downstream effectors are upregulated in $\mathrm{Er} \mathrm{T}^{\mathrm{C} \times /-}$ brains (Figure $3 \mathrm{~A}-\mathrm{B}$ ) at a level sufficient to 
elicit a type I-IFN response in IFN-responsive cells. In $\mathrm{Fr}^{\mathrm{Cx} /-}$ cerebella, we find that type I-IFN receptor (IFNAR) protein levels are higher in the neuronal population than in microglia cells; the latter is not evident in $\mathrm{Er}^{\mathrm{C} \mathrm{C} / \mathrm{-}}$ cortices or the hippocampi (Supplementary Figure S4B). Likewise, ifna and if $n \beta \mathrm{mRNA}$ levels are preferentially higher in the 6-months old $E r 1^{\mathrm{Cx} /-}$ cerebella compared to age-matched $\mathrm{Er}{ }^{\mathrm{Cx} /-}$ hippocampi or cortices indicating the marked sensitivity of neurons inhabiting the cerebellum to microglia-elicited type I-IFN stimuli (Supplementary Figure S5). To test whether type-I IFN-mediated stimuli affect the survival of Purkinje cells, we performed flow cytometry studies to evaluate the IFNAR protein levels in this neuronal cell type. Our analysis in the 6-months old $\mathrm{Er}^{\mathrm{Cx} /-}$ cerebella revealed that the great majority of Purkinje cells $(\sim 63 \%)$ have significantly higher IFNAR protein levels compared to the Purkinje cell population of littermate control animals (Figure 4E-F). Further analysis revealed that out of all IFNAR ${ }^{+}$cells in the $\mathrm{Er}^{\mathrm{CX} /}$ brain, Purkinje cells in the cerebellum are the only ones undergoing apoptosis (Figure 4G). Taken together, our findings indicate that ablation of ERCC1 in brain-resident macrophages is associated with loss of Purkinje cells that preferentially respond to microglia-elicited antiviral stimuli.

\section{$\mathrm{Er} 1^{\mathrm{Cx} /-}$ microglia secrete extracellular vesicles carrying $\mathrm{YH} 2 \mathrm{AX}$-associated chromatin. Secreted Type I}

IFNs enhance innate immune responses via autocrine and paracrine mechanisms and induce expression of ISGs that trigger apoptosis in targeted cells to inhibit viral replication and spread ${ }^{29}$. In this work, the presence of cytoplasmic chromatin fragments in $E r 7^{\mathrm{Cx} /-}$ microglia and the observed cell death of DNA repair-proficient Purkinje cells prompted us to examine whether microglia cells secrete extracellular vesicles (EVs) carrying chromatin fragments that, in turn, target IFNAR ${ }^{+}$Purkinje cells in $\mathrm{Er}^{\mathrm{Cx} /-}$ mice. In support, sucrose gradient ultracentrifugation and FACS analysis for CD11b revealed the increased presence of microglia-derived $\left(\mathrm{CD} 11 \mathrm{~b}^{+}\right) \mathrm{EVs}$ in the brain lavage of 6-months old $\mathrm{Er}{ }^{\mathrm{Cx} /-}$ mice compared to $\mathrm{ErT}^{\mathrm{F} /-}$ littermate control animals (Figure 5A). Scanning and transmission electron microscopy in this fraction revealed that microglia-derived EVs maintain a size of $\sim 100 \mathrm{~nm}$ (Figure $5 \mathrm{Bi}$ ); $\mathrm{Er}{ }^{\mathrm{Cx} /-}$ vesicles associate with a higher density cargo as shown by their darker center marking the presence of positively charged DNA moieties (also supported by the enriched phosphorus found by scanning electron microscopy analysis) surrounded by a double membrane (Figure 5Bii, Figure 5iii and Supplementary Figure S6). Western blot analysis confirmed the enrichment of CD11b and ALIX, known to be associated with the endosomal sorting complex required for transport ${ }^{30}$ (Figure 5B). FACS analysis with the DNA binding benzothiazole dye (PicoGreen) specific for dsDNA in microglia-derived CD11 $\mathrm{b}^{+} \mathrm{EV}$ s in the brain lavage of 6-months old $E r 7^{\mathrm{Cx} /-}$ and $\mathrm{Er}^{\mathrm{F} /-}$ animals revealed a significantly higher percentage of $\mathrm{Er} 7^{\mathrm{Cx} /-}$ EVs carrying dsDNA moieties (Figure $5 \mathrm{C}$ ). Further analysis revealed that the great majority of dsDNA

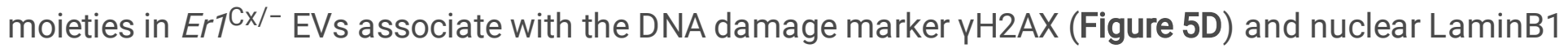
(Figure 5E) further confirming the nuclear origin of accumulated $\mathrm{\gamma H} 2 \mathrm{AX}$ chromatin structures in $\mathrm{Er} 7^{\mathrm{Cx} /-}$ $\mathrm{EVs}$. Western blot analysis of EVs derived from $\mathrm{Er} 7^{\mathrm{Cx} /-}$ and $\mathrm{Er}^{\mathrm{F} /-}$ brain lavages confirmed the enrichment of $\mathrm{YH} 2 \mathrm{AX}$ and LaminB1, P62, a reporter of autophagic activity ${ }^{25}$ and $\beta$-adaptin, one of the components of the AP-2 adaptor complex that binds ataxia telangiectasia-mutated gene (ATM) to assist with the 
trafficking of cytoplasmic vesicles ${ }^{31}$ (Figure 5B). Taken together, our findings suggest that $E r 7^{\mathrm{Cx} /-}$ microglia release EVs that are of nuclear origin carrying $\mathrm{YH} 2 \mathrm{AX}$-associated chromatin.

\section{Microglia-derived $\mathrm{Er}^{\mathrm{Cx} /-}$ EVs target IFNa-responsive Purkinje cells triggering apoptosis. Next, we sought} to examine whether Purkinje cells preferentially receive microglia-derived $E r 7^{\mathrm{Cx} /-} \mathrm{EVs}$. To do so, we exposed $\mathrm{Er}^{\mathrm{Fl}-}$ cultures of acute brain slices with $\mathrm{EV}$ s derived from 6-months old $\mathrm{Er}{ }^{\mathrm{Cx} /-}$ and $\mathrm{Er} 7^{\mathrm{F} /-}$ brains that were labeled with the lipophilic green fluorescent dye PKH67. To monitor the selective uptake of microglia-derived $\mathrm{Er}^{\mathrm{Cx} /-}$ EVs by calbindin ${ }^{+}$cells, we subjected $\mathrm{Er}^{\mathrm{F} /-}$ brain slices to simultaneous 2-3 multiphoton microscopy analysis allowing visualizing at least $200 \mu \mathrm{m}$ detection depths. The latter approach revealed that $\mathrm{Er}^{\mathrm{Cx} /-} \mathrm{EVs}$ are preferentially taken up by Purkinje cells when compared to $\mathrm{Er} \mathrm{F}^{\mathrm{Fl}-}$ $\mathrm{EVs}$; of note, the selective targeting of $\mathrm{Er}^{\mathrm{Cx} /-} \mathrm{EV}$ s to Purkinje cells is further propagated when $\mathrm{Er} 7^{\mathrm{Fl}-}$ brain slices are exposed to IFNa. (Figure 6A). Further work revealed the co-localization of PicoGreenstained dsDNA and calbindin in IFNa-treated $E r 7^{F /-}$ cerebella exposed to $E r 7^{\mathrm{Cx} /-} \mathrm{EVs}$ indicating that the preferential targeting of $E r 7^{\mathrm{Cx} /-}$ EVs to Purkinje cells is followed by the release of the $\mathrm{Er} 7^{\mathrm{Cx} /-} \mathrm{EV}$ dsDNA cargo in recipient cells (Figure 6B). Staining of acute brain slices with caspase-3 revealed that the exposure of IFNa-treated $E r 7^{F /-}$ brains to $E r 7^{\mathrm{Cx} /-} \mathrm{EVs}$ for 6 hours is sufficient to trigger Purkinje cell death (Figure $6 \mathrm{C}$ ). Thus, microglia-derived $E r 7^{\mathrm{Cx} /-} \mathrm{EVs}$ preferentially target and released their dsDNA cargo to IFNa-responsive Purkinje cells leading to apoptosis.

\section{Intranasal delivery of DNase Hoaded EVs delays the DNA damage-driven neurodegenerative features in} $\mathrm{Er}{ }^{\mathrm{Cx} /-}$ mice. To examine the functional contribution of accumulated $\mathrm{yH} 2 \mathrm{AX}$-associated chromatin fragments in the inflammatory response of $\mathrm{Er}^{\mathrm{C}} \mathrm{Cx}^{--}$microglia cells, we used $\mathrm{NIH} 3 \mathrm{~T} 3$ cells to generate EVs loaded with recombinant ( $\mathrm{pH}$-independent) DNase I. To maximize the selective targeting of DNase I EVs to $E r 1^{\mathrm{Cx} /-}$ microglia cells, the NIH3T3-derived EVs were also decorated with a custom anti-CD11b peptide derived from a combination of a CD63 binding sequence i.e. CRHSQMTVTSRL ${ }^{32}$ and the aMI-domain binding peptide $\mathrm{CP} 05$ i.e. RKLRSLWRR ${ }^{33}$. Using this approach, we find that exposure of $\mathrm{Er}^{\mathrm{C}} \mathrm{Cx} /{ }^{-}$microglia to DNase I EVs efficiently removes the great majority of cytoplasmic DAPI-stained chromatin fragments and ameliorates the DNA damage-driven LaminB1 disorganization in $\mathrm{Er}^{\mathrm{Cx} /{ }^{-}}$microglia nuclei (Figure 7A). Consistently, exposure of $\mathrm{Er}^{\mathrm{Cx} / \mathrm{-}}$ microglia to DNase I EVs leads to the marked decrease of secreted IFNa levels in the media of these cells (Figure 7B). We reasoned that the $\mathrm{NIH}$ - and microglia-derived EVs can be fused, thereby minimizing the DNA load of $\mathrm{Er}^{\mathrm{Cx} /-} \mathrm{EVs}$ to maximize the beneficial outcome of DNase Iloaded EVs. In agreement, FACS analysis of purified EVs from $E r 7^{\mathrm{CX} /-}$ brain lavages pre-stained with PicoGreen and co-incubated for 4 hours with DNase I-loaded or control EVs revealed that the microgliaderived $\left(\mathrm{CD} 11 \mathrm{~b}^{+}\right) \mathrm{Er} 7^{\mathrm{Cx} /-}$ EVs contain substantially less dsDNA compared to corresponding controls (Figure 7C). Next, we sought to test for the in vivo efficacy of DNase l-loaded EVs in ameliorating the neurodegenerative features seen in the 6-months old $\mathrm{Er}^{\mathrm{Cx} /{ }^{-}}$mice. To do so, 3-months old $\mathrm{Er}^{\mathrm{Cx} / \text { - }}$ animals were exposed to an intranasal delivery of DNase Hloaded EVs twice a week after treatment with a vasoconstrictor to prevent drainage of EVs from blood vessels into the tissues lining the nasal passages. Importantly, we find that treatment of $\mathrm{Er}^{\mathrm{Cx} /{ }^{-}}$animals with DNase I-EVs leads to the substantial decrease 
in Purkinje cell apoptosis (Figure 7D) and in the percentage of activated $\mathrm{MHCII}^{+} \mathrm{CD} 86^{+} \mathrm{Er}^{\mathrm{Cx} /{ }^{-}}$microglia cells (Figure 7E). Next, we monitored the motor coordination of the 3-months old $\mathrm{Er} 7^{\mathrm{Cx} /-}$ animals treated with DNase I-EVs by measuring the latency to fall from a rotarod apparatus. Our analysis revealed that hind limb coordination in the 3-months old $E r 7^{\mathrm{Cx} /-}$ mice treated with DNase I-EVs improves over a period of 6 weeks when compared to age-matched $\mathrm{Er}^{\mathrm{Cx} /-}$ mice treated with control EVs (Figure 7F). Further work revealed the substantial decrease of PicoGreen-stained dsDNA (Figure 7G) in the microglia-derived $\left(\mathrm{CD} 11 \mathrm{~b}^{+}\right) \mathrm{EVs}$ from $\mathrm{Er} \mathrm{T}^{\mathrm{Cx} /-}$ mice treated with DNase H-loaded EVs (Figure 7H). Thus, the intranasal delivery of DNasel-loaded EVs substantially reduces type I IFN levels and the microglia-derived dsDNAcarrying $\mathrm{EVs}$, thereby delaying the premature onset of neurodegenerative features seen in $\mathrm{Er} 7^{\mathrm{Cx} /-}$ mice. Taken together, our findings reveal that an intranasal delivery of DNase I EVs substantially decreases Purkinje cell death delaying the premature onset of neurodegenerative features seen in $\mathrm{Er}^{\mathrm{Cx} /-}$ mice.

\section{Discussion}

Until recently, endogenous DNA damage in post-mitotic neurons was thought to be the primary cause of age-related neurodegenerative disorders seen in DNA repair-deficient patients and accompanying animal models ${ }^{34}$. Using progeroid animals carrying a ERCC1-XPF DNA repair defect only in tissue-resident macrophages, we show that the gradual accumulation of persistent DNA lesions in brain microglia is sufficient to trigger Purkinje cell death and cerebellar ataxia in mice. Importantly, $E r 7^{\mathrm{Cx} /-}$ mice are born with Mendelian frequency, they grow normally, are fertile and show no visible pathological signs until adulthood. Beginning at 4-months, however, $E r 7^{\mathrm{Cx} /-}$ mice exhibit marked signs of cerebellar ataxia associated with Purkinje cell death. The latter is unexpected as in $\mathrm{Er}^{\mathrm{Cx} /-}$ animals, Purkinje cells are proficient in DNA repair with no signs of DNA damage accumulation. Instead, we find that irreparable DNA lesions lead to the buildup of H2AX-assciated chromatin fragments in the cytoplasm of NERdefective, tissue-resident $E r 7^{\mathrm{Cx} /-}$ macrophages. Importantly, cytoplasmic $\mathrm{H} 2 \mathrm{AX}$-associated chromatin fragments also accumulate in the microglial cells of naturally aged animals. Nuclear dsDNAs can passively diffuse into the cytosol when the nuclear envelope breaks down in mitotically dividing microglia cells ${ }^{18}$. In view of the DNA repair defect in $\mathrm{Er}^{\mathrm{Cx} /-}$ animals, the latter could also reflect a physiological response of the nucleus to remove byproducts of DNA damage repair or irreversibly damaged DNA fragments. Once accumulated in the cytoplasm of microglia cells, DNA moieties trigger the activation of a type I IFN response. An important finding is that $E r 7^{\mathrm{Cx} /-}$ microglia cells secrete $\mathrm{EVs}$ carrying $\mathrm{H} 2 \mathrm{AX}$ associated chromatin and that $\mathrm{Er} 7^{\mathrm{Cx} /-} \mathrm{EVs}$ target IFNa-responsive Purkinje cells in $\mathrm{Er} 7^{\mathrm{Cx} /-}$ cerebella. Of note, in $E r 7^{\mathrm{Cx} /-}$ animals, Purkinje cells have significantly higher IFNAR protein levels compared to littermate controls and are the only type of neurons undergoing apoptosis. Besides active targeting, the large size and multiple branching extensions of Purkinje cells likely explains how brain microglia inadvertently affect neuronal homeostasis and why Purkinje cells are particularly prone to microgliaderived stimuli. 
So far, the lack of knowledge on the causal mechanisms underlying DNA damage-driven inflammation has hindered the development of rationalized intervention strategies against degenerative diseases, especially at older ages. EVs are non-immunogenic carriers allowing their therapeutic cargo to circulate for extended periods within the body ${ }^{35}$. To alleviate neuroinflammation, we developed an EV-based strategy to deliver recombinant DNase 1 nuclease in inflamed $E r 7^{\mathrm{CX} /-}$ microglia cells in vivo. We show that the EV-delivered nuclease cargo rapidly removes dsDNAs from the cytoplasm of microglia cells as well of microglia-derived $E r 1^{C X /-} \mathrm{EVs}$, thereby maximizing the beneficial outcome of the treatment. At the cellular level, we find that the EV-based removal of cytoplasmic DNAs restores LaminB1 disorganization in the nuclear membrane of $\mathrm{Er}^{\mathrm{Cx} /-}$ microglia cells and considerably lowers the secreted IFNa levels in microglia cell culture media. In mice, the EV-based therapeutic strategy lowers the percentage of activated $\mathrm{Er}^{\mathrm{Cx} /-}$ microglia cells leading to the substantial decrease of Purkinje cell death that considerably improves motor coordination in $\mathrm{Er}^{\mathrm{CX} /-}$ animals. Thus, as DNA damage-associated chromatin fragments accumulate over time, an EV-based therapeutic scheme is a promising strategy to combat age-related neuroinflammation and improve the outcome of neurodegenerative disorders with aging ${ }^{10,36}$.

\section{Materials And Methods}

Animals. Animals homozygous for the floxed $\operatorname{Ercc} 1$ allele $\left(\operatorname{Ercc} 1^{\mathrm{F} / \mathrm{F}}\right)$ were intercrossed with mice carrying the CX3CR1-Cre transgene in an Ercc1 heterozygous background ( $\mathrm{Er}^{\mathrm{CX} /{ }^{-}}$animals). Mice lacking the CX3CR1-Cre transgene in an Ercc1 homozygous background were used as wild-type controls $\left(E r 1^{F /+}\right)$. All animals were maintained in grouped cages in a temperature-controlled, pathogen-free animal facility (IMBB-FORTH) on a 12h light/dark cycle and were fed a normal diet (Lactamin, Stockholm, Sweden). Mice had access to water ad libitum. This work received ethical approval by independent Animal Ethical Committee at IMBB-FORTH. All relevant ethical guidelines for the work with animals were adhered to during this study.

Primary cell isolation and cell assays. For single cell isolation from whole brains or selected brain areas (cortex, cerebellum, hippocampus), brains from $\mathrm{Er}^{\mathrm{CX} /{ }^{-}}$and $\mathrm{Er}^{\mathrm{F} /+}$ animals were excised, washed in icecold full medium (DMEM containing 10\% FBS, $50 \mathrm{\mu g} / \mathrm{ml}$ streptomycin, $50 \mathrm{U} / \mathrm{ml}$ penicillin (Sigma) and 2 $\mathrm{mM} \mathrm{L-glutamine} \mathrm{(Gibco)),} \mathrm{minced} \mathrm{and} \mathrm{incubated} \mathrm{in} 2 \mathrm{mg} / \mathrm{ml}$ collagenase type IV at $37^{\circ} \mathrm{C}$ for $45 \mathrm{~min}$. Collagenase activity was halted with the addition of ice-cold medium to the resultant homogenate. After centrifugation, cells were resuspended in DMEM and further homogenized using a syringe ( $21 \mathrm{G}$ needle). Filtration through a sterile pre-moistened $40 \mu \mathrm{m}$ cell strainer was used to separate the clumped cells, meninges and tissue fragments. Following centrifugation, cells were resuspended in full medium. Primary microglial cells were isolated through $\mathrm{CD}_{11} \mathrm{~b}^{+}$magnetic-bead selection after density gradient centrifugation on Percoll. Briefly, Percoll density gradient was prepared in polystyrene tubes by layering $5 \mathrm{ml}$ of $35 \%$ Percoll solution on top of $3 \mathrm{ml} 75 \%$ Percoll solution, in which the brain cells were resuspended after the final centrifugation. $2 \mathrm{ml}$ of 1XPBS were loaded on top of the Percoll density gradient and microglia along with lymphocytes were separated by centrifugation at $800 \mathrm{~g}$ for $40 \mathrm{~min}$ at $4^{\circ} \mathrm{C}$. The cell band formed between the 75 and 35\% layer was harvested, cells were washed with PBS and diluted in 
standard growth medium. For $\mathrm{CD}_{11} \mathrm{~b}^{+}$microglia cell isolation, the human and mouse CD11b (microglia) Microbeads (MACS, Miltenyi Biotec) were used. Microglia cells at a density of $>50.000$ cells per well were placed either on poly-L-lysine coated glass coverslips in a 24-well plate or directly in each well of 24-well plate, depending on the experiment. For the LPS treatment $(50 \mathrm{ng} / \mathrm{ml})$, microglia cells were plated on wells of a 24-well plate and incubated at $37^{\circ} \mathrm{C}$ for $24 \mathrm{hrs}$. For confocal microscopy, microglia cells were plated (and cultured where needed) on poly-L-lysine treated coverslips and were incubated at $37^{\circ} \mathrm{C}$ for 18 hrs and $3 \mathrm{hrs}$, respectively. All treatments were performed 20min after their complete attachment on culture plate/slide.

Immunochemistry on primary neuronal and microglia cells. Whole brain and brain areas (cortex, cerebellum, hippocampus) from $\mathrm{Er}^{\mathrm{CX} /{ }^{-}}$and $\mathrm{Er} 7^{\mathrm{F} /+}$ animals were excised and neuronal and microglia cells were isolated as previously described. Once isolated, cells were placed on poly-L-lysine coated coverslips, fixed with $4 \%$ F/A for 15 min maximum, RT and washed $3 \mathrm{X}$ with $1 \mathrm{X}$ PBS, for $5 \mathrm{~min}, \mathrm{RT}$. Permeabilization/Blocking was performed (B1 solution:1\% BSA,0,5\% Triton in $1 \mathrm{X}$ PBS) for $1 \mathrm{~h}$, RT. Primary antibodies in $\mathrm{B} 1$ solution were added on the coverslips, $\mathrm{O} / \mathrm{N}$, at $4^{\circ} \mathrm{C}$. The following day, coverslips were washed thrice (B2 solution: 0,5\% Triton in 1X PBS) for 10min, RT and secondary antibodies were added, along with DAPI for $2 \mathrm{~h}$. Finally, coverslips were washed thrice with B2 solution for $10 \mathrm{~min}$, RT and then they were put on microscope slides with $80 \%$ glycerol. Imaging was performed using SP8 confocal microscope (Leica).

Histology, Immunohistochemistry. $E r 1^{C x /-}$ and $E r 1^{F /+}$ animals were perfused and their brains were dissected, embedded in gelatin-sucrose, frozen and kept at $-80^{\circ} \mathrm{C}$. Brains were then cryosectioned (tissue sections were either used directly or stored at $-20^{\circ} \mathrm{C}$ ). For the immunohistochemistry experiments, cryosections were stained following two different protocols. According to the Digitonin protocol, cryosections were encircled using Dako - Pen and were then incubated in 1XPBS, RT for $5 \mathrm{~min}$. The samples were further incubated in Glycine, for $5 \mathrm{~min}$, RT. Three washing steps followed with 1X PBS, for $6 \mathrm{~min}, \mathrm{RT}$ and blocking in a solution of $0.01 \%$ Digitonin in 1 XPBS, RT, for $45-60 \mathrm{~min}$. The primary antibody solution was placed $\mathrm{O} / \mathrm{N}$ at $4^{\circ} \mathrm{C}$. Samples were immunostained with the corresponding fluorescently labeled antibodies for $2 \mathrm{~h}$, RT. A separate 10-min incubation was carried out in DAPI and the slides were coverslipped with $80 \%$ Glycerol. Three 6 min washes with a solution of $0.2 \%$ Triton in 1X PBS were performed in between incubations. According to the Triton-X protocol, cryosections were encircled using Dako - Pen and post-fixed in ice-cold acetone at $-20^{\circ} \mathrm{C}$, for 10 minutes. Three washing steps followed with 1 X PBS, for $5 \mathrm{~min}$, at RT and blocking in a solution of $5 \%$ bovine serum albumin (BSA) in $0,5 \%$ Triton$X$ in $1 X$ PBS at RT, for $1 \mathrm{~h}$. Tissue sections were incubated with the primary antibody solution, $0 / \mathrm{N}$ at $4^{\circ} \mathrm{C}$. Samples were immunostained with the corresponding fluorescently labeled antibodies for 1.5h, RT. A separate $10 \mathrm{~min}$ incubation was carried out in DAPI and the slides were coverslipped with $80 \%$ Glycerol. Three $5 \mathrm{~min}$ washes with 1X PBS were performed in between incubations. For histological analysis of $\mathrm{ErT}^{\mathrm{F} / \mathrm{+}}$ and $\mathrm{Er} 7^{\mathrm{CX} /-}$ tissues, samples were fixed in $4 \%$ formaldehyde, paraffin embedded, sectioned and stained with Harris's Hematoxylin and Eosin Y solution. The TUNEL Staining was performed on brain cryosections using the in situ cell death detection kit, Fluorescein (11684817910, Roche Diagnostics, 
Mannheim, Germany), according to the manufacturer's protocol. In brief, the sections were fixed in $4 \%$ formaldehyde for $1 \mathrm{~h}$, rinsed with PBS (5 min, 2 times) RT and permeabilized in 0,1\% Triton in 0,1\% sodium citrate at $4^{\circ} \mathrm{C}$, for $8 \mathrm{~min}$. The slides were again rinsed with PBS ( $5 \mathrm{~min}, 2$ times), and incubated in $50 \mu \mathrm{L}$ TUNEL reaction mixture for $1 \mathrm{~h}$ at $37^{\circ} \mathrm{C}$, dark. The reaction was terminated by rinsing the samples with PBS (5min, 2 times) and the sections were sealed and detected by a light microscope. The nuclei were stained with DAPI (1:500). A positive control was also performed using DNase I (50U/ml), MNase $(10 \mathrm{U} / \mathrm{ml})$ and proteinase $\mathrm{K}(20 \mu \mathrm{g} / \mathrm{ml})$.

Quantitative PCR (QPCR). Quantitative PCR was performed with a CFX Connect Real-Time PCR Detection system device (BIORAD). The generation of specific PCR products was confirmed by melting curve analysis. Each primer pair was tested with a logarithmic dilution of a cDNA mix to generate a linear standard curve (crossing point (CP) plotted versus log of template concentration), which was used to calculate the primer pair efficiency $\left(E=10^{(-1 / \text { slope })}\right)$. Hypoxanthine guanine phosphoribosyltransferase1 (Hprt-1) mRNA was used as an external standard. For data analysis, the second derivative maximum method was applied: ( $E_{1 \text { gene of interest }} \triangle \mathrm{CP}$ (cDNA of wt. mice - CDNA of Ercc1F/-) gene of interest) $/\left(E_{h p r t-1} \triangle C P(\mathrm{cDNA}\right.$ wt. mice- cDNA) hprt-1).

Hprt F: CCCAACATCAACAGGACTCC, Hprt R: CGAAGTGTTGGATACAGGCC, IFNa F: CTGCTGGCTGTGAGGACATA, IFNa R: GGCTCTCCAGACTTCTGCTC, IFN $\beta$ F: TGAACTCCACCAGCAGACAG, IFN $\beta$ R: AGATCTCTGCTCGGACCACC, ISG15 F: GGTGTCCGTGACTAACTCCAT, ISG15 R:

TGGAAAGGGTAAGACCGTCCT, IFIT2 F: AGTACAACGAGTAAGGAGTCACT, IFIT2 R: AGGCCAGTATGTTGCACATGG, MX1 F: GACCATAGGGGTCTTGACCAA, $M X 1 R$ : AGACTTGCTCTTTCTGAAAAGCC, IFIT1 F: CCAAGTGTTCCAATGCTCCT, IFIT1 R: GGATGGAATTGCCTGCTAGA, IRF1 F: GGAAGGGAAGATAGCCGAAG, IRF1 R: GGGCTGTCAATCTCTGGTTC, IFI207 F: CAGGCTCAGCTTTCAGAACC, IFI207 R: ATTTCCTGAGGACCCCTTGT, IFI44 F: AACTGACTGCTCGCAATAATGT, IFI44 R: GTAACACAGCAATGCCTCTTGT

EV isolation, labelling, loading and treatments. EVs were purified using the differential ultracentrifugation protocol. Briefly culture medium was centrifuged sequentially at $300 \mathrm{~g},(10 \mathrm{~min}), 2000 \mathrm{~g} \mathrm{(10} \mathrm{min),} \mathrm{and}$ $10000 \mathrm{~g}$ (30 min) to remove dead cells and cell debris. Extracellular vesicles were isolated with an ultracentrifugation at $100.000 \mathrm{~g}$ for $2 \mathrm{~h}$ and were then purified using a $90-10 \%$ sucrose gradient. Purified EVs were collected after a final ultracentrifugation at $100.000 \mathrm{~g}$ for $2 \mathrm{~h}$. All ultracentrifugations were performed at $4^{\circ} \mathrm{C}$. For PKH67 staining, EVs were incubated with PKH67 (company, $500 \mathrm{~mL} 0.2 \mathrm{mM}$ ) for 5 min at room temperature (RT). Labelled EVs were diluted in $500 \mathrm{~mL} 1 \%$ BSA, and then pelleted at 100,000 $\mathrm{g}$, washed with $1 \mathrm{~mL}$ PBS to remove excess dye, re-suspended in $1 \mathrm{~mL}$ PBS and then pelleted at 100,000 $\mathrm{g}$ before final re-suspension. For the extravesicular labelling of EVs against antibodies and fluorochromes, brain lavage-derived EVs were incubated with both of them at dark, (20 min) RT. For intravesicular staining, exosomes were fixed with $0.01 \%$ formaldehyde $(15 \mathrm{~min})$ at $4^{\circ} \mathrm{C}$, washed with $0,2 \%$ saponin, 5\% BSA in 1xPBS (permeabilization/blocking buffer) and finally isolated after ultracentrifugation at $4^{\circ} \mathrm{C}, 100.000 \mathrm{~g}$ for $2 \mathrm{~h}$. EVs were re-suspended and incubated in blocking buffer for 
$30 \mathrm{~min}, 4^{\circ} \mathrm{C}$ and then the immunofluorescently-labeled primary antibody was added. EVs were incubated with the primary antibody for $45 \mathrm{~min}, 4^{\circ} \mathrm{C}$ and the secondary fluorescently labeled antibody was added together with DAPI. For EV loading with DNase I and peptide tagging, EVs from NIH3T3 $(4 \times 107)$ cells were isolated and permeabilized with $0.2 \%$ saponin for 15 min at RT. Exosomes were then incubated with 30 units of DNase I (Pulmozyme, Roche) and the chimeric peptide (3518; $1 \mu \mathrm{g} / 1 \mu \mathrm{g} \mathrm{EVs):}$

CRHSQMTVTSRLRKLRSLWRR at $4^{\circ} \mathrm{C}$ for $4 \mathrm{hrs}$. For the EV-to-EV fusion experiment, EVs were isolated as described above, tagged, loaded, labelled and incubated at $4^{\circ} \mathrm{C}$ for $4 \mathrm{hrs}$. EVs from NIH3T3 cells $(4 \times 107)$ were isolated and half of them were loaded with DNase I (Pulmozyme, Roche) and the chimeric peptide $(3518,1 \mu \mathrm{gr} / 1 \mu \mathrm{g} \mathrm{EVs})$, as it was previously described, while the rest remained empty (naive EVs). Their administration was performed intranasally twice a week for 6 weeks, in 3-month-old mice and its effect on the motor coordination of $E r 1^{C X /-}$ mice was monitored by rotarod latency assay.

Immunoblot analysis and antibodies. Immunoblotting brain cells were lysed in RIPA buffer (50 mM Tris$\mathrm{HCl}$ at $\mathrm{pH} 8,150 \mathrm{mM} \mathrm{NaCl}, 0.5 \%$ sodium deoxycholate, $1 \%$ Nonidet P-40 and 0.1\% SDS) supplemented with protease and phosphatase inhibitors (Complete EDTA Free; Roche Applied Science) and equal amounts of proteins $(50 \mu \mathrm{gr})$ were subjected to SDS-PAGE on $7 \%, 10 \%$ and $14 \%$ gels and then transferred to PVDF membrane (Amersham Hybond). Membranes were blocked with $5 \%$ skimmed milk or $5 \%$ BSA in TBST and then incubated with primary antibodies. For western blot analysis of EVs, EV pellets were resuspended in $5 X$ Laemli buffer, sonicated for 5 circles and loaded in the gel. Samples were normalized using antibodies for housekeeping genes ( $\beta$-tubulin). The image was resolved by ECL system (Thermo Fisher Scientific and Amersham) and detected by ImageBlot (BIORAD). Relative intensity of bands was calculated with Fiji software. Antibodies against: LC3 (C-9, WB:1:500, IF: 1:500), ERCC1 (D-10, WB:1:500, IF: 1:50), LaminB1 (ab16048, WB:1:1000), p62 (SQSTM1, MBLPM045, WB:1:5000, IF:1:1000) and goat anti-rat IgG-CFL 647 (sc-362293, IF: 1:500) were from Santa Cruz Biotechnology. $\mathrm{Y}-\mathrm{H} 2 \mathrm{~A} . \mathrm{X}$ (05-636, IF: 1:12000) and pATM (05-740, IF: 1:100) were from Millipore. $\beta$-Tubulin (ab6046, WB:1:1000), $\gamma-H 2 A . X$ (ab22551, WB: 1:1000), ERCC1 (ab129267, IF: 1:150) and Calbindin (ab108404, IF: 1:150) were from Abcam or (C9848, IF: 1:500) from Sigma Aldrich. ALIX (\#2171, WB: 1:500), pSTING (\#72971, WB: 1:1000), STING (136475, WB: 1:1000), CD81 (10037, WB: 1:1000) and Cleaved Caspase-3 (\#9661, IF-IC: 1:300, IHC-F: 1:200) were from Cell Signaling Technology. CD45 (H5A5, IF: 1:200) and MAC1 (M1/70.15.11.5.2, IF: 1:200) were from Developmental Studies Hybridoma Bank (DSHB). PKH67 Green Fluorescent Cell Linker Midi Kit (MIDI67) was from Sigma Aldrich. NeuN (26975-1-Ap, IF: 1:50-1:500) was from Proteintech. MBP1 (IF: 1:200) was from Serotec. Fluoromyelin (F34652, IF: 1:300) was from Molecular probes. $\beta$-adaptin gr(PA1-1066, WB, IF: $2 \mu \mathrm{g} / \mathrm{ml})$, Goat anti-Mouse IgG $(\mathrm{H}+\mathrm{L})$ Cross-Adsorbed Secondary Antibody, Alexa Fluor 488 (A-11001, IF: 1:500), Goat anti-Mouse IgG (H+L) Cross-Adsorbed Secondary Antibody, Alexa Fluor 555 (A-21422, IF:1:500), Donkey anti-Rabbit lgG (H+L) Highly Cross-Adsorbed Secondary Antibody, Alexa Fluor 488 (A-21206, IF:1:500), Goat anti-Rabbit IgG (H+L) Highly CrossAdsorbed Secondary Antibody, Alexa Fluor 555 (A-27039, IF:1:500) and DAPI (62247, IF:1:500) were from ThermoFisher/Invitrogen. 
Flow cytometry. Cells and $\mathrm{EVs}$ from $\mathrm{Er} 7^{\mathrm{Cx} /-}$ and $\mathrm{Er} 7^{\mathrm{F} /+}$ animals were isolated and stained with fluorochrome conjugated antibodies for $20 \mathrm{~min}$ at $4^{\circ} \mathrm{C}$ in PBS $/ 5 \%$ FBS. Antibodies used were: anti-Ly6C (128007, clone HK1.4), anti-IFNAR (Invitrogen, clone MAR1-5A3), anti-CD11b (101212, 101208, clone M1 170), anti-MHCII (107606, clone M5/114.15.2) and anti-CD86 (105026, clone GL-1). For intracellular staining, cells were permeabilized and stained using the True-Nuclear Transcription Factor Buffer Set (424401, BioLegend). Secondary antibodies used were: anti-mouse IgG, PerCP (F0114) conjugated goat $\mathrm{F}(\mathrm{ab})_{2}$ and Alexa Fluor 488 (A-11001). Live cells were also stained for Annexin V/PI using the FITC Annexin V Apoptosis Detection Kit (556547, BD Pharmingen). Samples were acquired on a FACS Calibur (BD Biosciences) and analyzed using the FlowJo software (Tree Star). FSC SSC scatter was gated for live cells (those on axes were excluded as cell debris or cell clusters). Positive staining was considered that of MFI more or equal to $10^{\wedge} 1$. In all cases, the same number of events (for cells or EVs) were acquired from all samples tested per experiment.

Electron microscopy. For electron microscopy (EM) analysis of EVs, fixed EVs were deposited on EM grids and were further fixed with glutaraldehyde. Samples were first contrasted in a solution of uranyl oxalate and then contrasted and embedded in a mixture of $4 \%$ uranyl acetate and $2 \%$ methyl cellulose. EVs were examined under JEM 100C/JEOL/Japan Transmission Electron Microscope. For scanning electron microscopy, isolated EVs were diluted in distilled water and were deposited on glass slides. EVs were examined under Scanning Electron Microscope.

\section{Multiphoton microscopy}

A single wavelength fs laser source was used to excite simultaneously three- and two- photon fluorescence ( $3 p-F$ and $2 p-F$, respectively) and perform three - color multiphoton imaging microscopy in the acute brain slices. For this purpose, a custom-build multiphoton microscope (Supplementary Figure S7A) was used, based on a $1030 \mathrm{~nm}$ fs laser (Pharos-SP, Light Conversion, Vilnius, Lithuania), which is passing through a pair of galvanometric mirrors ( $6215 \mathrm{H}$, Cambridge Technology, Bedford, MA, USA) before entering into an inverted microscope (Axio Observer Z1, Carl Zeiss, Jena, Germany) ${ }^{37,38}$. The beam is then reflected by a short pass dichroic mirror (FF700-SDi01, Semrock, Rochester, NY, USA) placed at the turret box of the microscope and is focused in to the sample plane with a 20x $0.8 \mathrm{NA}$ objective-lens (Plan-Apochromat 20x/0.8NA, Carl Zeiss). The emitted fluorescence is collected by the same objective and is filtered by a short pass filter (FF01-680/SP, Semrock) to ensure that no laser light is reaching the detectors. Then, the beam is split by a long-pass dichroic mirror (509-FDi01, Semrock), which reflects wavelengths shorter than $509 \mathrm{~nm}$ and let pass wavelengths longer than $509 \mathrm{~nm}$. The reflected wavelengths are further filtered by a band-pass filter (FF1-458/64, Semrock), which allows passing the wavelengths in the range of $458 \pm 32 \mathrm{~nm}$ ) before reaching a detector, based on a photomultiplier tube PMT-blue (H9305-04, Hamamatsu, Hizuoka, Japan). The transmitting wavelengths longer than 509 nm, are reaching a second long-pass dichroic mirror (FF-580-FDi01, Semrock) which reflects the wavelengths shorter than $580 \mathrm{~nm}$ and let pass the wavelengths longer than $580 \mathrm{~nm}$. The reflected wavelengths are further filtered by a band-pass filter (FF01-527/20, Semrock), which allows passing the wavelengths in the range of $527 \pm 10 \mathrm{~nm}$ ) before reaching a second detector, the PMT-green (H9305-04, Hamamatsu). 
Finally, the wavelengths longer than $580 \mathrm{~nm}$ are passing through a band-pass filter (FF-595/31, Semrock), which allows passing the wavelengths in the range of $595 \pm 15.5$ ) before reaching the third PMT-red (H9305-04, Hamamatsu). In our experiments the PMT-blue detects the fluorescence emitted from the dye DAPI, while the PMT-green and the PMT-red detect the fluorescence originating from the dyes Alexa Fluor 488 (or PKH67) and Alexa Fluor 555, respectively (Supplementary Figure S7B-C). Quantification of colocalization analysis was performed using JACoP plugin in ImageJ, while the co-localization indicators presented in Figure 6 were calculated using the Manders' coefficient ${ }^{39}$.

B16 - Blue ${ }^{T M}$ IFN- $\alpha / \beta$ cell line / SEAP levels detection. B16-Blue ${ }^{T M}$ IFN- $\alpha / \beta$ cells derive from the murine B16 melanoma cell line of C57BL/ 6 origin and allow the detection of bioactive murine type I IFNs by monitoring the activation of the JAK/STAT/ISGF3 pathway and/or IRF3 pathway. Stimulation of B16Blue $^{\text {TM }}$ IFN- $\alpha / \beta$ cells with murine IFN- $\alpha$ or IFN- $\beta$, or type I IFN inducers, such as poly(I:C), poly (dA:dT) or 5'ppp-dsRNA delivered intracellularly, triggers the production of SEAP (Secreted embryonic alkaline phosphatase) by the activation of the IRF-inducible promoter. For the B16-Blue cell cultures, cells were transferred to a T-25 tissue culture flask containing DMEM, 10\% (v/v) heat-inactivated FBS, $100 \mathrm{U} / \mathrm{ml}$ penicillin, $100 \mu \mathrm{g} / \mathrm{ml}$ streptomycin, $100 \mu \mathrm{g} / \mathrm{ml}$ Normocin and $2 \mathrm{mM} \mathrm{L-glutamine.} \mathrm{No} \mathrm{selective} \mathrm{antibiotics}$ were added at that point, since cells have to be passaged twice before antibiotics addition. Cells were maintained in growth media supplemented with $100 \mu \mathrm{g} / \mathrm{ml}$ of Zeocin. Growth medium was renewed twice a week and cells were inspected daily. Cells were passaged at a 70-80\% confluency. For the detection and quantification of SEAP levels, a cell suspension of 420.000 cells $/ \mathrm{ml}$ in growth medium was prepared. 75.000 cells in growth medium were added per well ( 24 well plate) along with culture media from previous experiments and the plate was incubated at 37\% in 5\% CO2 overnight. QUANTI-Blue solution (1 $\mathrm{ml}$ QB reagent, $1 \mathrm{ml}$ QB Buffer and $98 \mathrm{ml}$ sterile water) was prepared the following day, from which $180 \mu \mathrm{l}$ were added in each well of a 96 well plate. Duplicates of induced B16-Blue cells' supernatants were added, along with a positive (murine IFNa) and negative control (growth medium). The plate was incubated at $37^{\circ} \mathrm{C}$ for $3 \mathrm{~h}$. After $3 \mathrm{~h}$ incubation, SEAP levels were detected by using a spectrophotometer (Techam) at 620-655 nm.

Acute brain slices (SNAPSHOT method). Brains from $\mathrm{Er}^{\mathrm{CX} /-}$ and $\mathrm{Er}^{\mathrm{F} /+}$ animals were excised and sliced $(400 \mu \mathrm{m})$ using a vibratome. Acute brain slices were transferred in a 12-well plate containing fresh ACSF (artificial cerebrospinal fluid). Slices were treated with labelled or unlabeled exosomes, with or without the addition of IFNa protein (12100-1, 4.99 $\times 10^{6}$ units/ml, 1:200, PBL assay science) and were then incubated at $37^{\circ} \mathrm{C}$ for $4 \mathrm{~h}$. A 2 min fixation followed, with the slices being transferred in a 12-well plate containing heated $\left(80^{\circ} \mathrm{C}\right)$ PFA. The slices were rinsed with $0.1 \mathrm{M}$ PBS to remove residual PFA. The plate was placed on a platform rotator. Slices were permeabilized in 1 phosphate-buffered saline (PBS) tablet, $2 \mathrm{ml}$ Triton $\mathrm{X}-100(2 \% \mathrm{v} / \mathrm{v}$ final) and $20 \mathrm{ml}$ DMSO (20\% v/v final) for a minimum of $2 \mathrm{hr}$. Non-target epitopes were blocked by incubation with blocking solution (washing solution with $10 \%$ FBS) overnight at RT. Primary antibodies along with DAPI were diluted to the required concentrations in staining solution (washing solution with $2.5 \%$ FBS) and each slice was incubated with the diluted primary antibodies in a small plastic bag made by using a Manual Impulse Sealer for 6 to 10 days at $4^{\circ} \mathrm{C}$ on a platform rotator or a 
$360^{\circ}$ rotisserie wheel. After incubation with primary antibodies, slices were washed with permeabilizing/washing solution three to five times over the course of a day. Secondary antibodies, along with DAPI were diluted to the required concentrations in staining solution and slices were incubated with the diluted secondary antibodies in a small plastic bag for 4 to 6 days at $4^{\circ} \mathrm{C}$ on a platform rotator or a $360^{\circ}$ rotisserie wheel. Fluorophores were protected from exposure to light by wrapping the bags in aluminum foil. The acute brain slices were washed once again with permeabilizing/washing solution three to five times over the course of a day and they were incubated with DAPI for 4 more hours. Acute brain slices were then rinsed three to five times in PBS and prepared for imagining. To image the tissue slices, each slice was placed on a microscope slide prepared with the slide, cover glasses, and Krazy Glue, using a transfer pipet with the tip cut off. A small drop of PBS was added on top of the brain slice before the placement of the cover glass over the brain slice. Finally, corn oil was added to each side of the microscope slide and imaging was performed with a two-photon scanning microscope.

Rotarod assay. To assess motor impairment, $E r 1^{C X /-}$ and $E r 1^{F /+}$ animals were subjected to rotarod assay test. Briefly, mice need to keep their balance on a rotating rod by walking forward. One day before testing, mice were trained at a constant rotating mode of $5 \mathrm{rpm}$ for $2 \mathrm{~min}$. During testing, mice were initially placed in their lanes, with the rod rotating at 5-rpm constant speed to allow their positioning. Once all mice were able to walk forward, the acceleration test was performed, in which the rod accelerated from 5 $\mathrm{rpm}$ to $70 \mathrm{rpm}$ in $60 \mathrm{sec}$. The time (latency) it took each mouse to fall off the rod rotating under continuous acceleration (from 5 to $70 \mathrm{rpm}$ ) was recorded, as well as the reason for trail end (e.g., falling, jumping). The temperature, humidity, ventilation, noise intensity and lighting intensity were controlled and maintained at levels appropriate for mice. All mice were kept in a uniform environment before and after testing to avoid anomalous results being obtained.

Quantification and Statistical analysis. A two-tailed t-test was used to extract the statistically significant data by means of the IBM SPSS Statistics 19 (IBM) and the $R$ software for statistical computing (www.rproject.org). Data analysis is discussed also in the Method Details section. Experiments were repeated at least 3 times. The data exhibited normal distribution (where applicable). There was no estimation of group variation before experiments. Error bars indicate standard deviation unless stated otherwise (standard error of the mean; s.e.m.). For animal studies, each biological replicate consists of 3-5 mouse tissues or cell cultures per genotype per time point or treatment. No statistical method was used to predetermine sample size. None of the samples or animals was excluded from the experiment. The animals or the experiments were non-randomized. The investigators were not blinded to allocation during experiments and outcome assessment.

\section{Declarations}

\section{Acknowledgments}

The Horizon 2020 ERC Consolidator grant "DeFiNER" (GA64663), the Horizon 2020 Marie Curie ITNs "Chromatin3D" (GA622934), "aDDRess" (GA812829) and "HealthAge" "(GA812830), the Hellenic 
Foundation for Research and Innovation (HFRI) and the General Secretariat for Research and Technology (GSRT) under grant agreement HFRI-1059 and HFRI-FM17-631, the "Fondation Santé" grant and the EDBM MIS: 5048456 supported this work.

\section{Author Contributions}

KG, ET, EA, EN, GN, EG, SP, IK, DK and MS performed the experiments and/or analyzed data. GG interpreted data and wrote the manuscript. All relevant data are available from the authors.

\section{Competing interests}

The authors declare no competing interests.

\section{References}

1. Hoeijmakers, J. H. Genome maintenance mechanisms for preventing cancer. Nature 411, 366-374 (2001).

2. McKinnon, P. J. DNA repair deficiency and neurological disease. Nat Rev Neurosci 10, 100-112, doi:10.1038/nrn2559 (2009).

3. McKinnon, P. J. Maintaining genome stability in the nervous system. Nat Neurosci 16, 1523-1529, doi:10.1038/nn.3537 (2013).

4. Apostolou, Z., Chatzinikolaou, G., Stratigi, K. \& Garinis, G. A. Nucleotide Excision Repair and Transcription-Associated Genome Instability. Bioessays 41, e1800201, doi:10.1002/bies.201800201 (2019).

5. Kamileri, I., Karakasilioti, I. \& Garinis, G. A. Nucleotide excision repair: new tricks with old bricks. Trends in genetics: TIG 28, 566-573, doi:10.1016/j.tig.2012.06.004 (2012).

6. Niedernhofer, L. J. et al. The structure-specific endonuclease Ercc1-Xpf is required to resolve DNA interstrand cross-link-induced double-strand breaks. Mol Cell Bio/ 24, 5776-5787, doi:10.1128/MCB.24.13.5776-5787.2004 (2004).

7. Shanbhag, N. M. et al. Neurodegeneration as the presenting symptom in 2 adults with xeroderma pigmentosum complementation group F. Neurol Genet 4, e240, doi:10.1212/NXG.0000000000000240 (2018).

8. Gregg, S. Q., Robinson, A. R. \& Niedernhofer, L. J. Physiological consequences of defects in ERCC1XPF DNA repair endonuclease. DNA Repair (Amst) 10, 781-791, doi:10.1016/j.dnarep.2011.04.026 (2011).

9. Jaspers, N. G. et al. First reported patient with human ERCC1 deficiency has cerebro-oculo-facioskeletal syndrome with a mild defect in nucleotide excision repair and severe developmental failure. 
Am J Hum Genet 80, 457-466, doi:10.1086/512486 (2007).

10. Chatzinikolaou, G., Karakasilioti, I. \& Garinis, G. A. DNA damage and innate immunity: links and tradeoffs. Trends Immuno/ 35, 429-435, doi:10.1016/j.it.2014.06.003 (2014).

11. Stratigi, K., Chatzidoukaki, O. \& Garinis, G. A. DNA damage-induced inflammation and nuclear architecture. Mech Ageing Dev 165, 17-26, doi:10.1016/j.mad.2016.09.008 (2017).

12. Karakasilioti, I. et al. DNA damage triggers a chronic autoinflammatory response, leading to fat depletion in NER progeria. Cell Metab 18, 403-415, doi:10.1016/j.cmet.2013.08.011 (2013).

13. Tilstra, J. S. et al. NF-kappaB inhibition delays DNA damage-induced senescence and aging in mice. J Clin Invest 122, 2601-2612, doi:10.1172/JCI45785 (2012).

14. Davies, L. C., Jenkins, S. J., Allen, J. E. \& Taylor, P. R. Tissue-resident macrophages. Nat Immunol 14, 986-995, doi:10.1038/ni.2705 (2013).

15. Yona, S. et al. Fate mapping reveals origins and dynamics of monocytes and tissue macrophages under homeostasis. Immunity 38, 79-91, doi:10.1016/j.immuni.2012.12.001 (2013).

16. Stence, N., Waite, M. \& Dailey, M. E. Dynamics of microglial activation: a confocal time-lapse analysis in hippocampal slices. Glia 33, 256-266 (2001).

17. Fernandez-Capetillo, O., Lee, A., Nussenzweig, M. \& Nussenzweig, A. H2AX: the histone guardian of the genome. DNA repair 3, 959-967, doi:10.1016/j.dnarep.2004.03.024 (2004).

18. Harding, S. M. et al. Mitotic progression following DNA damage enables pattern recognition within micronuclei. Nature 548, 466-470, doi:10.1038/nature23470 (2017).

19. Rello-Varona, S. et al. Autophagic removal of micronuclei. Cell Cycle 11, 170-176, doi:10.4161/cc.11.1.18564 (2012).

20. Hartlova, A. et al. DNA damage primes the type I interferon system via the cytosolic DNA sensor STING to promote anti-microbial innate immunity. Immunity 42, 332-343, doi:10.1016/j.immuni.2015.01.012 (2015).

21. Perry, A. K., Chen, G., Zheng, D., Tang, H. \& Cheng, G. The host type I interferon response to viral and bacterial infections. Cell Res 15, 407-422, doi:10.1038/sj.cr.7290309 (2005).

22. Ishikawa, H. \& Barber, G. N. STING is an endoplasmic reticulum adaptor that facilitates innate immune signalling. Nature 455, 674-678, doi:10.1038/nature07317 (2008).

23. Klionsky, D. J. et al. Guidelines for the use and interpretation of assays for monitoring autophagy in higher eukaryotes. Autophagy 4, 151-175 (2008).

24. Dou, Z. et al. Autophagy mediates degradation of nuclear lamina. Nature 527, 105-109, doi:10.1038/nature15548 (2015).

25. Komatsu, M. et al. Homeostatic levels of p62 control cytoplasmic inclusion body formation in autophagy-deficient mice. Cell 131, 1149-1163, doi:10.1016/j.cell.2007.10.035 (2007).

26. Gkirtzimanaki, K. et al. IFNalpha Impairs Autophagic Degradation of mtDNA Promoting Autoreactivity of SLE Monocytes in a STING-Dependent Fashion. Cell Rep 25, 921-933 e925, doi:10.1016/j.celrep.2018.09.001 (2018). 
27. Niedernhofer, L. J. Nucleotide excision repair deficient mouse models and neurological disease. DNA Repair (Amst) 7, 1180-1189 (2008).

28. Biton, S., Barzilai, A. \& Shiloh, Y. The neurological phenotype of ataxia-telangiectasia: solving a persistent puzzle. DNA Repair (Amst) 7, 1028-1038, doi:10.1016/j.dnarep.2008.03.006 (2008).

29. McNab, F., Mayer-Barber, K., Sher, A., Wack, A. \& O'Garra, A. Type I interferons in infectious disease. Nat Rev Immunol 15, 87-103, doi:10.1038/nri3787 (2015).

30. Raposo, G. \& Stoorvogel, W. Extracellular vesicles: exosomes, microvesicles, and friends. J Cell Biol 200, 373-383, doi:10.1083/jcb.201211138 (2013).

31. Lim, D. S. et al. ATM binds to beta-adaptin in cytoplasmic vesicles. Proc Natl Acad Sci U S A 95, 10146-10151, doi:10.1073/pnas.95.17.10146 (1998).

32. Gao, X. et al. Anchor peptide captures, targets, and loads exosomes of diverse origins for diagnostics and therapy. Sci Trans/ Med 10, doi:10.1126/scitransImed.aat0195 (2018).

33. Podolnikova, N. P., Podolnikov, A. V., Haas, T. A., Lishko, V. K. \& Ugarova, T. P. Ligand recognition specificity of leukocyte integrin alphaMbeta2 (Mac-1, CD11b/CD18) and its functional consequences. Biochemistry 54, 1408-1420, doi:10.1021/bi5013782 (2015).

34. McKinnon, P. J. Genome integrity and disease prevention in the nervous system. Genes Dev 31, 1180-1194, doi:10.1101/gad.301325.117 (2017).

35. Sterzenbach, U. et al. Engineered Exosomes as Vehicles for Biologically Active Proteins. Mol Ther 25, 1269-1278, doi:10.1016/j.ymthe.2017.03.030 (2017).

36. Ioannidou, A., Goulielmaki, E. \& Garinis, G. A. DNA Damage: From Chronic Inflammation to AgeRelated Deterioration. Front Genet 7, 187, doi:10.3389/fgene.2016.00187 (2016).

37. Xydias, D. et al. Three-dimensional characterization of collagen remodeling in cell-seeded collagen scaffolds via polarization second harmonic generation. Biomed Opt Express 12, 1136-1153, doi:10.1364/BOE.411501 (2021).

38. Kourgiantaki, A. et al. Neural stem cell delivery via porous collagen scaffolds promotes neuronal differentiation and locomotion recovery in spinal cord injury. NPJ Regen Med 5, 12, doi:10.1038/s41536-020-0097-0 (2020).

39. Bolte, S. \& Cordelieres, F. P. A guided tour into subcellular colocalization analysis in light microscopy. J Microsc 224, 213-232, doi:10.1111/j.1365-2818.2006.01706.x (2006).

\section{Figures}


A.
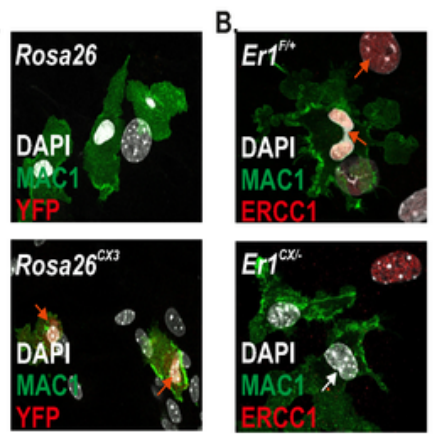

C.

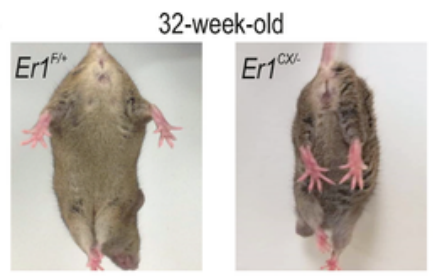

D.

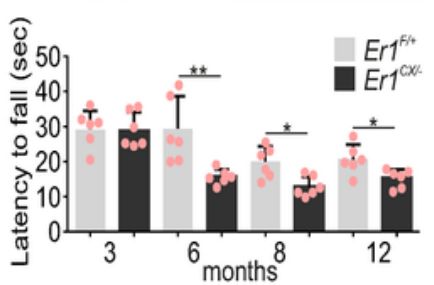

E.
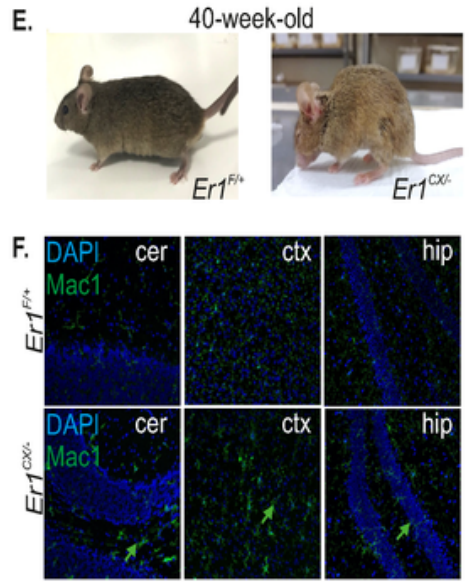

G.

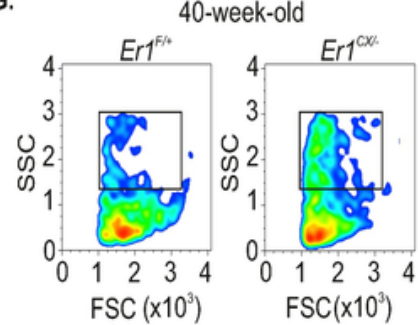

H.
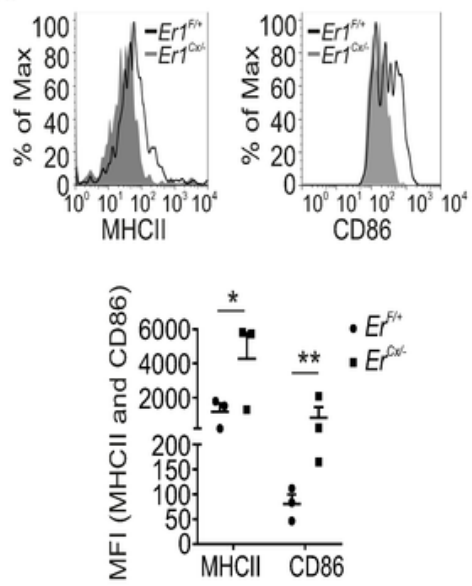

I.

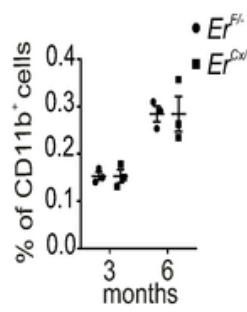

J.

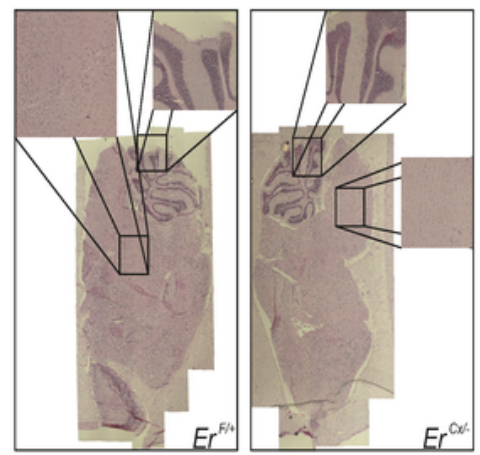

K.

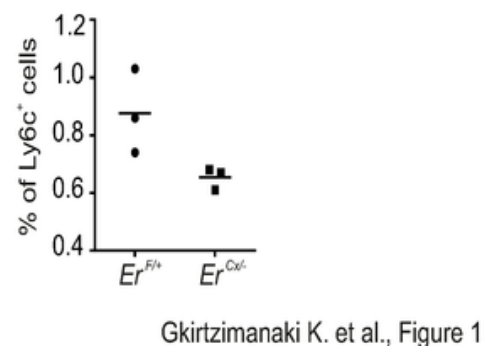

\section{Figure 1}

Loss of ERCC1 in tissue-resident macrophages triggers progressive ataxia in mice. (A). CX3CR1-Credriven Rosa-YFP expression in tissue-resident macrophages and (B). ERCC1 protein staining indicating cell type-specific ablation of ERCC1 in CX3CR1-Ercc1F/- cells (Er1CX/-) indicated by the respective arrows. (C). A photograph of a 32-week-old Er1CX/- mouse and its control littermate depicting the hind limb paralysis developed in $\mathrm{Er} 1 \mathrm{Cx} /$ - mice. (D). A graph depicting the latency to fall (seconds on the 
rotating rod) during Rotarod assessment of the motor coordination of 3-, 6-, 8 and 12-months old Er1 Cx/mice and littermate Er1F/+ controls, $n=6$ mice per group (E). A photograph showing the kyphosis developed in 40-week-old Er1Cx/- mice. (F). MAC1/CD11b immunofluorescent staining of microglia cells (green arrow) and DAPI staining in cerebellum (cer), cortex (ctx) and hippocampus (hip) Er1CX/- and Er1F/+ brain slices. (G). FACS analysis of freshly isolated brain microglia from an Er1F/+ and an Er1CX/mouse of the same age and sex. Higher SSC (black box) indicates higher granularity/vesicle content. $(H)$. Activation status of freshly isolated microglia from Er1CX/- mice and Er1F/+ littermates. The histogram overlays MHCII (up) and CD86 (down) expression in MHCll+CD86+ cells. The graph shows the respective MFIs from three independent experiments. (I). Graph depicting the percentage (\%) of CD11b+ cells in single cell suspensions of 3-6 months old Er1CX/- and Er1F/+ mouse brains. Statistical analysis indicated no significant differences. $(\mathrm{J})$. Representative image of a Hematoxylin- and Eosin-stained sagittal section of 8-months old Er1CX/- and Er1F/+ mice. (K). Graph depicting the percentage (\%) of Ly6C+ cells in single cell suspensions of Er1CX/- and Er1F/+ mouse brains. Statistical analysis indicated no significant differences. The asterisk " $*$ " indicates a p-value $\leq 0.05$, two-tailed Student's t-test. 
A.

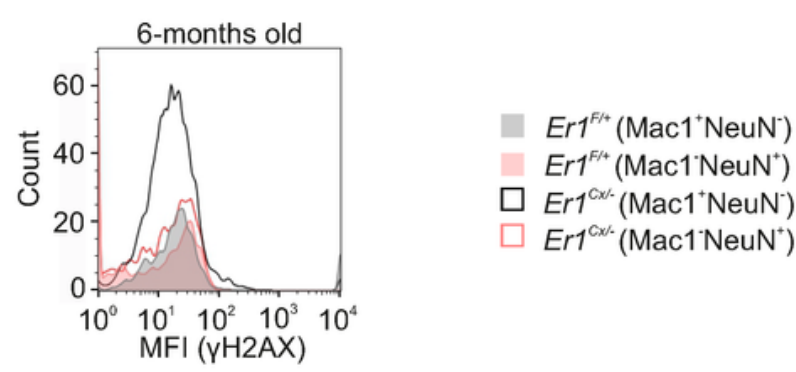

B.
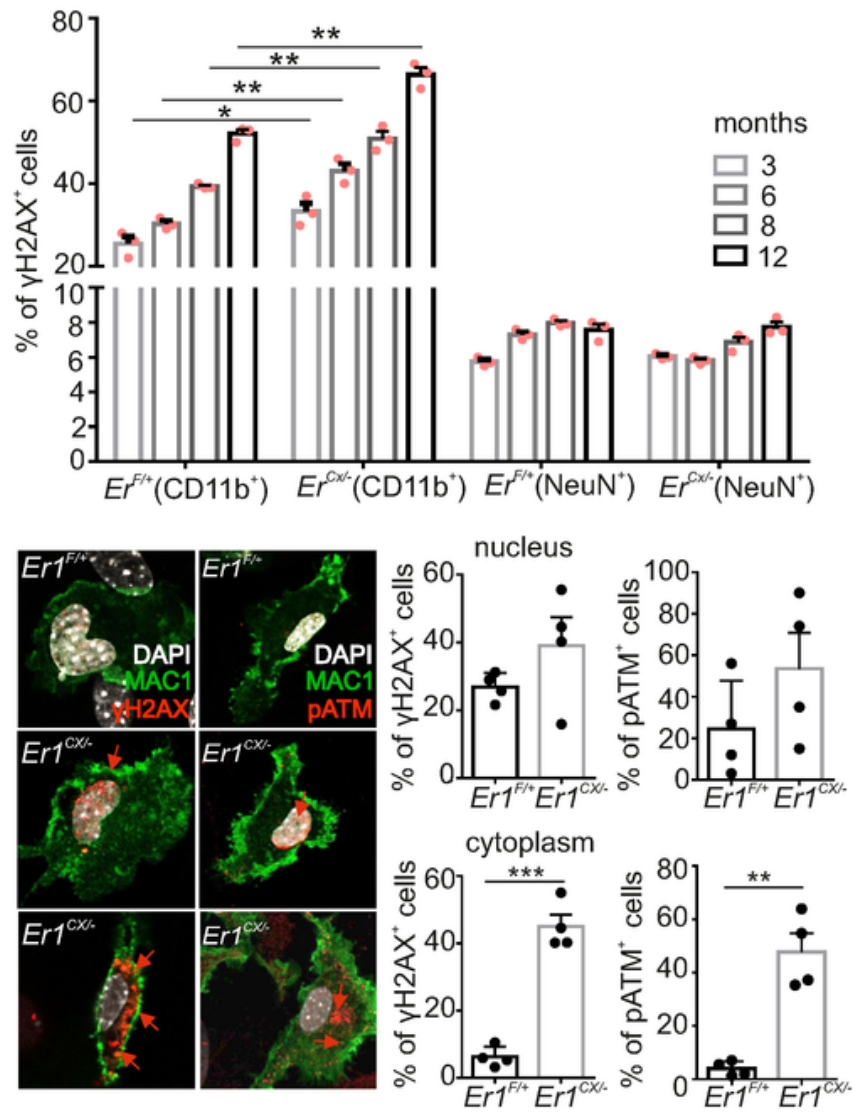

C.
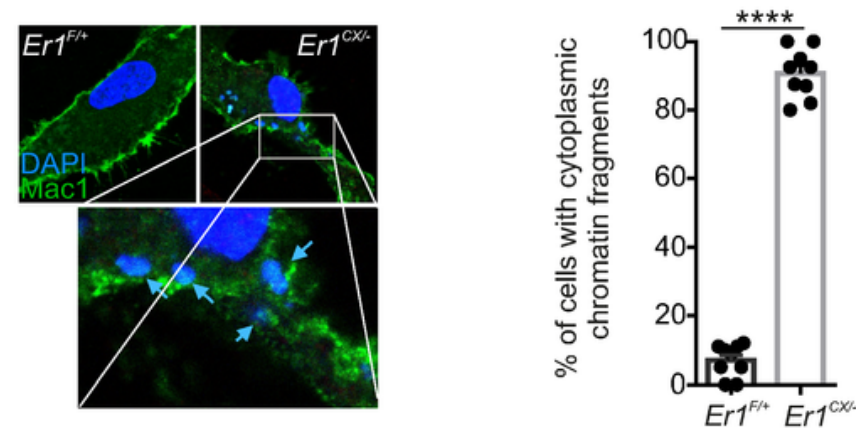

Gkirtzimanaki K. et al., Figure 2

Figure 2

Persistent DNA damage triggers the accumulation of cytoplasmic chromatin fragments in Er1Cx/microglia. (A). FACS analysis for $\mathrm{YH} 2 \mathrm{AX}, \mathrm{NeuN}$ and MAC1/CD11b in freshly isolated brain single cell suspensions of $\mathrm{Er} 1 \mathrm{~F} /+$ and $\mathrm{Er} 1 \mathrm{CX} /$ - brains. The histogram depicts the representative overlay of $\mathrm{YH} 2 \mathrm{AX}$ fluorescence intensity distribution in $\mathrm{CD} 11 \mathrm{~b}$ or NeuN cell populations in the 6-months old Er1CX/- and Er1F/+ brains. The graph depicts the percentage (\%) of $\mathrm{yH} 2 \mathrm{AX}+$ microglia cells (CD11b) and neurons 
(NeuN) in the 3-, 6-, 8- and 12-months old Er1CX/- and Er1F/+ brains (as indicated). (B). Immunostaining for MAC1/CD11b (green), YH2AX (red) and pATM (red) on brain single cell suspensions. The graphs depict the percentage (\%) of cells with cytoplasmic or nuclear YH2AX or pATM puncta (C). Immunostaining for MAC1/CD11b (green) and intensified DAPI in freshly isolated microglia cells from Er1CX/- and Er1F/+ brains; the inlay depicts the DAPI-stained chromatin in the cytoplasm of Er1CX/microglial cells. The graph depicts the percentage (\%) of cells with cytoplasmic chromatin fragments. The white line is set at $5 \mu \mathrm{m}$ scale. Error bars indicate S.E.M. among $n \geq 3$ replicates. The asterisk " $\star$ " indicates a p-value $\leq 0.05$, two-tailed Student's t-test. 
A.

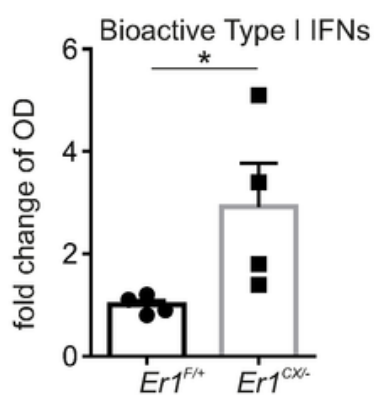

c.

D.
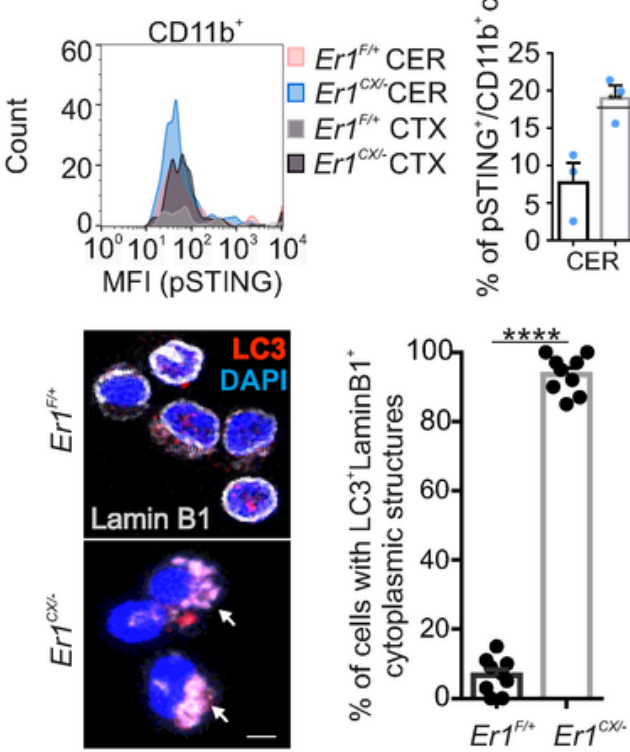

E.
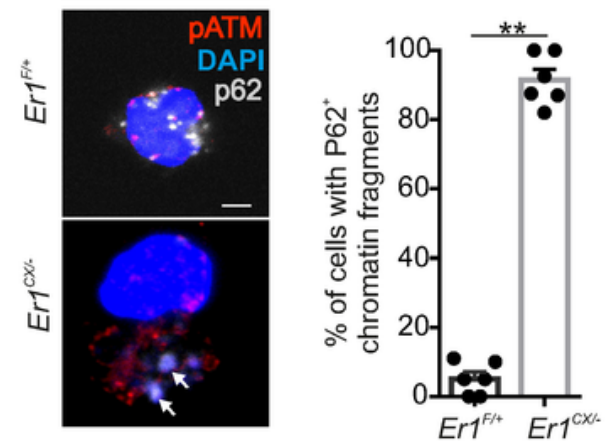

F.
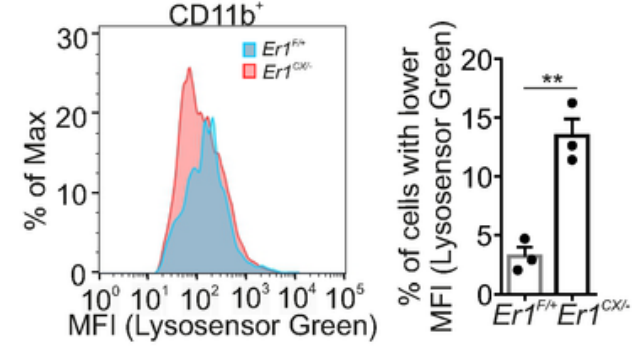

崩
ISG mRNA levels

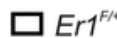

$\square E r 1^{c x-}$
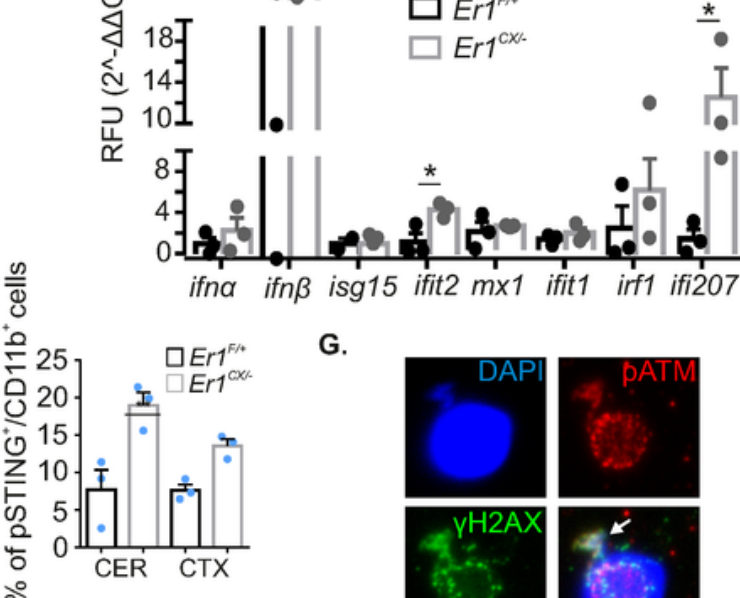

G.
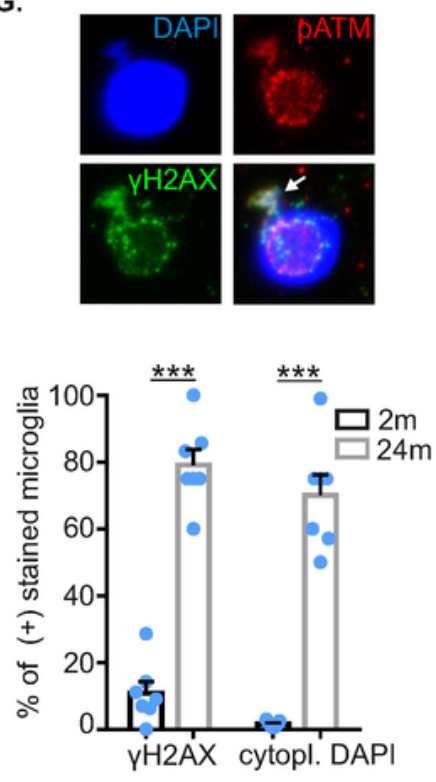

H.
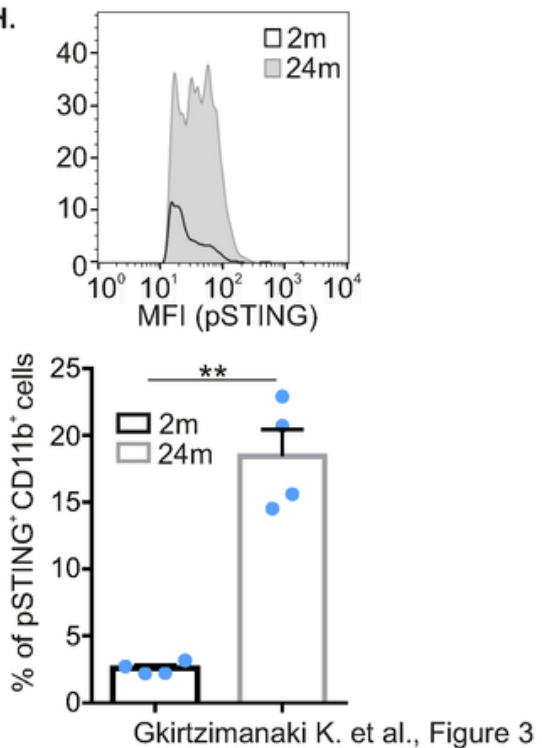

Figure 3

Accumulation of cytoplasmic chromatin fragments triggers a type I IFN response in Er1Cx/- microglia. (A). Type I IFN bioactivity (B16 reporter assay OD fold change) in 6-months old Er1Cx/- and agedmatched Er1F/- brain lavages ( $n=4)$. (B). Quantitative PCR evaluation of the mRNA levels of interferon signature genes in the brain lysates of 6-months old Er1F/+ and Er1CX/- mice (as indicated; RFU: relative fluorescent units; n=3). (C). FACS analysis of pSTING intracellular levels in CD11b+ brain cells derived 
from the cerebella (CER) or cortices (CTX) of 6 -months old Er1F/+ and Er1CX/- mice ( $n=3)$. (D). Immunostaining for LC3 and LaminB1 in freshly isolated microglial cells of 6-months old Er1CX/- and $\mathrm{Er} 1 \mathrm{~F} /+$ brains. The graph depicts the percentage (\%) of cells with reorganized LaminB1 (E). Immunostaining for PATM and p62/SQTM1 in freshly isolated microglial cells of 6-motnhs old Er1CX/and $\mathrm{Er} 1 \mathrm{~F} /+$ brains. The graph depicts the percentage (\%) of Er1CX/- or Er1F/+ cells with cytoplasmic DAPI+ P62+ chromatin structures. (F). FACS analysis of Lysosensor Green in freshly isolated brain microglia derived from 6-months old Er1F/+ and Er1CX/- brains. The representative histogram overlay of Lysosensor Green MFI shows the significant decrease in Er1CX/- cells. The graph depicts the percentage (\%) of cells with lower Lysosensor Green MFI. (G). Immunostaining for YH2AX (green) and cytoplasmic DAPI staining of freshly isolated microglia cells derived from 24-months old naturally aged cerebella. $(H)$. FACS analysis of pSTING intracellular levels in CD11b+ cells derived from the cerebella of 2- and 24months naturally aged mice $(n=3)$. The white line is set at $5 \mu \mathrm{m}$ scale. Error bars indicate S.E.M. among $\mathrm{n} \geq 3$ replicates. The asterisk " $\star$ " indicates a $\mathrm{p}$-value $\leq 0.05$, two-tailed Student's t-test. 
A.

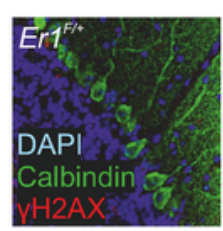

B.
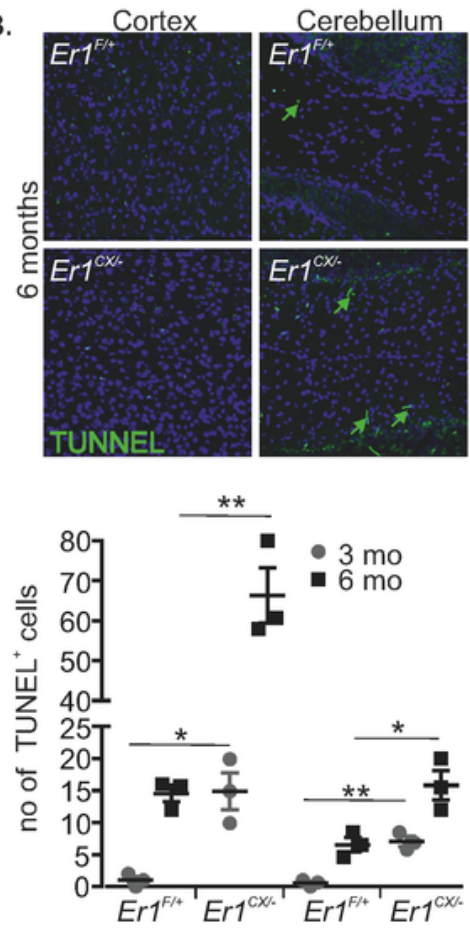

C.

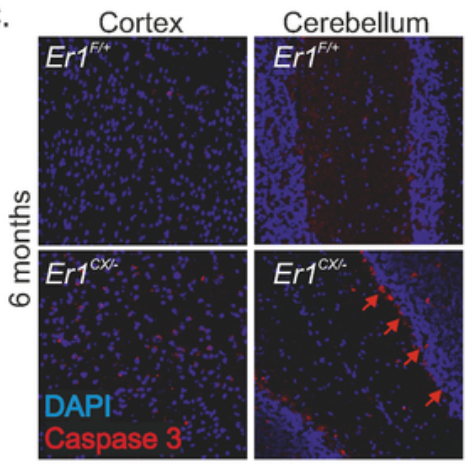

D.

$\bar{\alpha}$

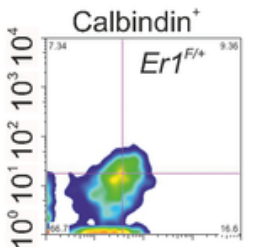

$10^{\circ} 10^{1} 10^{2} 10^{3} 10^{4}$ MFI (Annexin V)
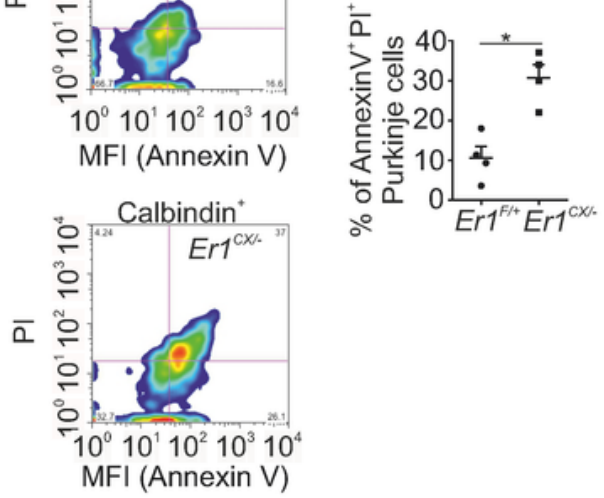

E.
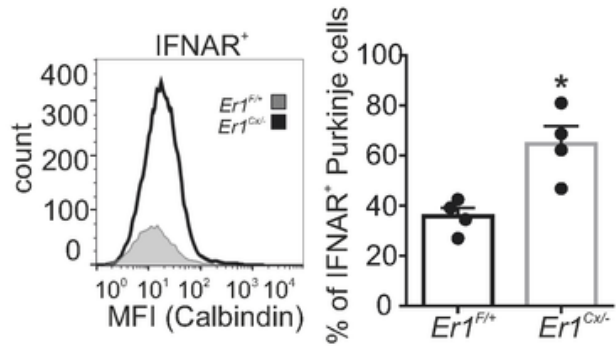

F.

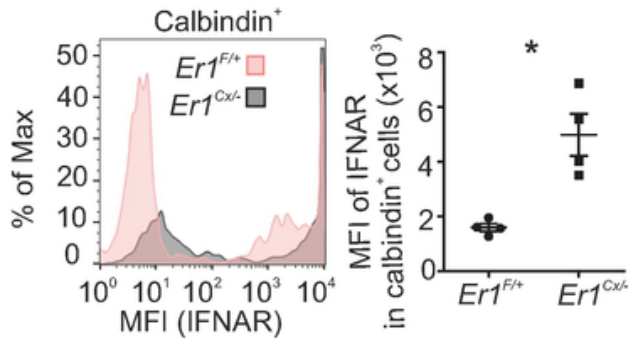

G.

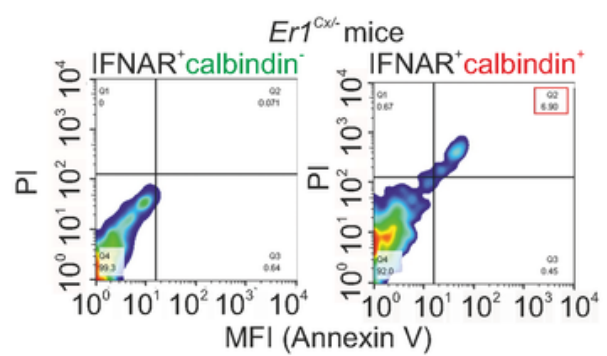

Gkirtzimanaki K. et al., Figure 4

\section{Figure 4}

Aged microglia elicit antiviral-like response that preferentially kills Purkinje neurons. (A). Immunostaining for $\mathrm{YH} 2 \mathrm{AX}$ (red), calbindin (green) and DAPI in brain sections derived from Er1CX/- and Er1F/+ mice ( $\mathrm{n}=3$ animals per group, 2 sections per mouse). (B). Representative images of Apoptotic cell death (indicated by green-colored arrowheads; TUNEL) and DAPI staining in brain sagittal sections of distinct brain areas associated with motility regulation (cerebellum, cerebral cortex) of 6-months old Er1CX/- and Er1F/+ 
animals. The graph depicts the number of TUNEL positive cells in the cortex and cerebellar brain sections of 3- and 6-months old mice ( $\mathrm{n}=3$ animals per group, 4 sections per mouse). (C). Immunostaining for apoptotic cleaved-caspase 3 (red) and DAPI in sagittal brain sections of 6-months old Er1CX/-animals and Er1F/+ littermate controls; red arrowheads indicate the caspase 3 staining in the Purkinje cell layer of Er1CX/- cerebellar cortex. (D). Representative FACS plots of Annexin V-Propidium lodide (PI) scatter of calbindin+ cells. The graph depicts the percentage (\%) Annexin V+PI+ Purkinje cells (E). A representative histogram overlay (FACS analysis) of freshly isolated single cell suspensions from of Er1CX/- and Er1F/+ brains stained for IFNAR and calbindin. The graph depicts the percentage (\%) of IFNAR+ Purkinje cells $(n=4)$. (F). A representative histogram overlay of IFNAR expression in Purkinje cells derived from 6months old Er1CX/- and Er1F/+ animals. The graph depicts the MFI of IFNAR expression in calbindin+ cells $(n=4)$. $(G)$. FACS representative plots of Er1CX/- freshly isolated brain single cell suspensions stained for IFNAR, calbindin, Annexin V and PI. The white line is set at $5 \mu \mathrm{m}$ scale. Error bars indicate S.E.M. among $n \geq 3$ replicates. The asterisk “»” indicates a p-value $\leq 0.05$, two-tailed Student's t-test. 
A.
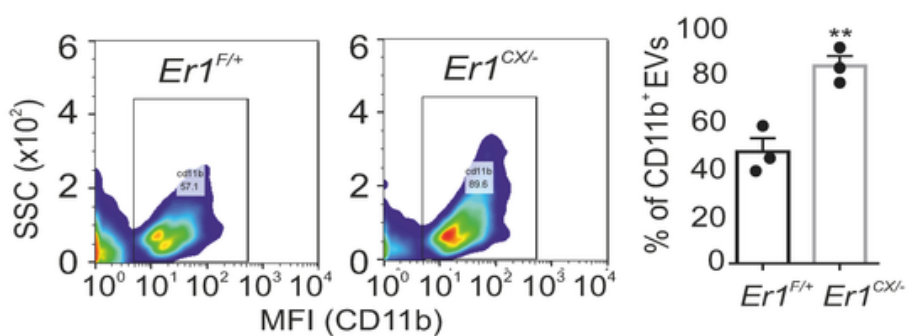

B.
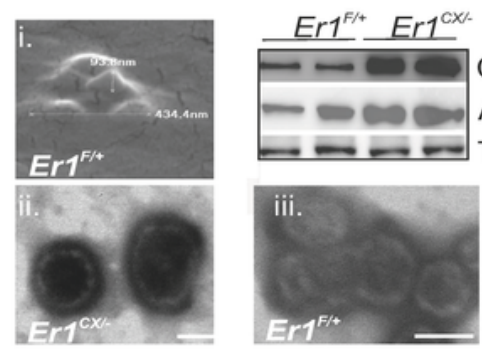

c.
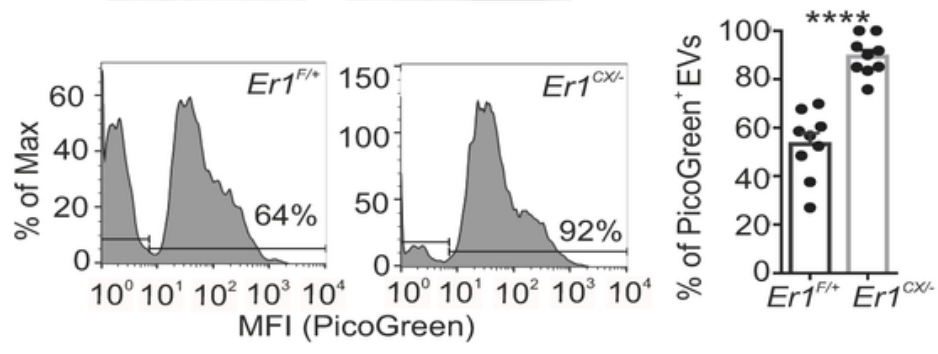

D.

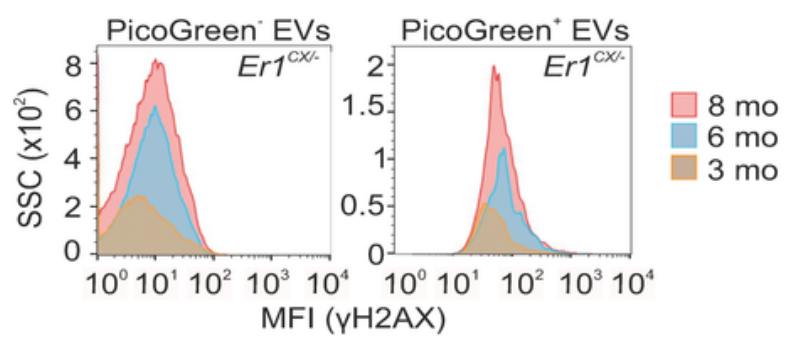

E.

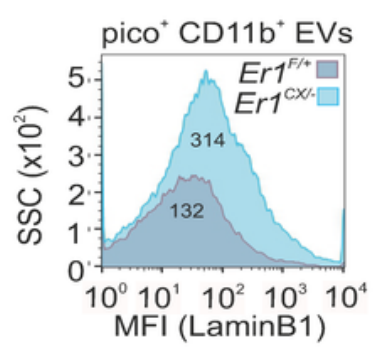

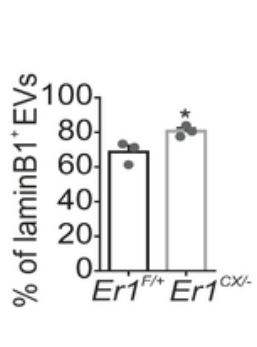

$\mathrm{F}$.

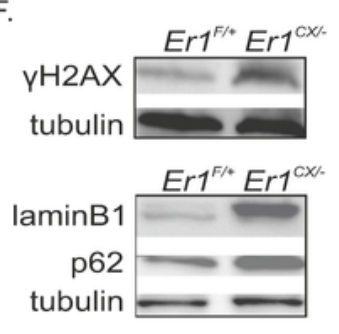

Gkirtzimanaki K. et al., Figure 5

\section{Figure 5}

Er1CX/- microglia release EVs carrying dsDNAs associated with DNA damage. (A). FACS analysis of extracellular vesicles purified with sucrose gradient centrifugation from 6-months old Er1F/+ and Er1CX/brain lavages stained for CD11b. (B). Scanning (i) and Transmission (ii-iii) electron microscope images of purified circulating EVs from Er1F/+ Er1CX/- brain lavages. Western blot analysis of CD11b, ALIX and Tubulin proteins levels in purified circulating EVs from Er1F/+ Er1CX/- brain lavages $(n=3)$. (C). FACS 
analysis of purified EVs from Er1F/+ and Er1CX/- brain lavages stained for CD11b and PicoGreenTM $(n=3)$. The graph depicts the \% of dsDNA carrying CD11b+ EVs. (D). FACS analysis of purified EVs from 3-, 6- and 8-months old Er1CX/- brain lavages stained for $\mathrm{YH} 2 \mathrm{AX}$ (intravesicularly), CD11b and PicoGreenTM. The histogram overlays depict the $\mathrm{YH} 2 \mathrm{AX}$ MFI distribution between PicoGreenTM - and PicoGreenTM + EV populations across the indicated age groups. (E). FACS analysis of purified EVs from $\mathrm{Er1F} /+$ and Er1CX/- brain lavages stained for CD11b, PicoGreenTM and LaminB1. The graph depicts the $\%$ of laminB1 + EVs $(n=3)$. (F). Western blot analysis of $\mathrm{YH} 2 \mathrm{AX}$, LaminB1, $\beta$-adaptin, P62 and tubulin in purified EVs from Er1F/+ and Er1CX/- brain lavages $(n=3)$. The asterisk " “" indicates a p-value $\leq 0.05$, two-tailed Student's t-test. 
A.
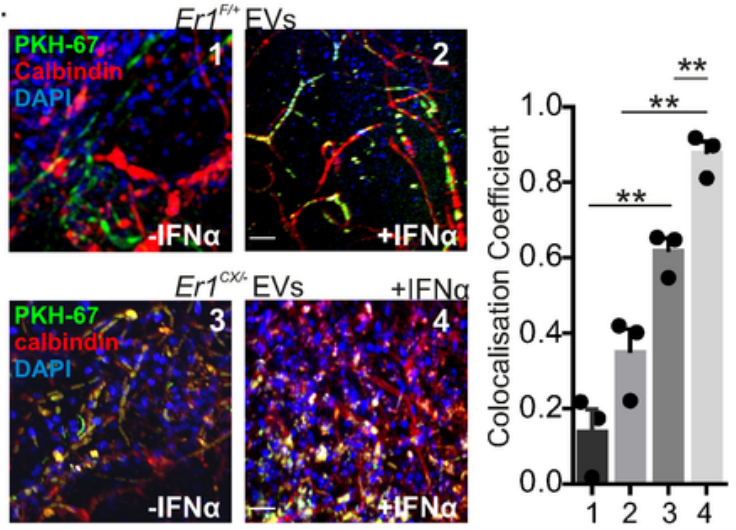

B.

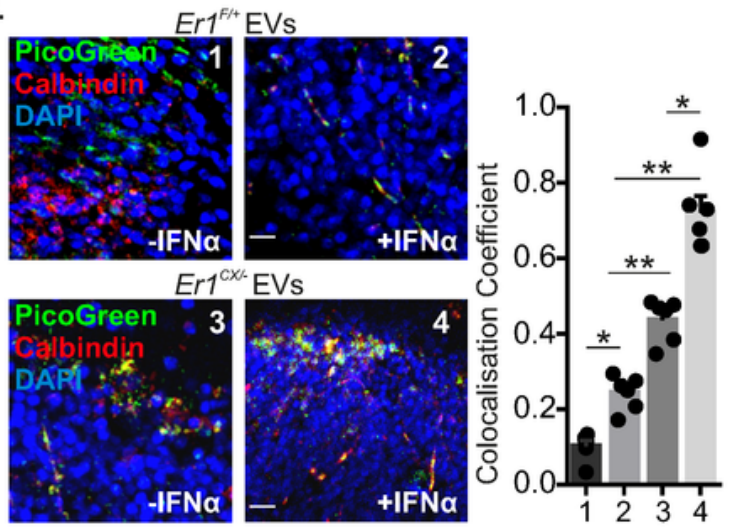

C.
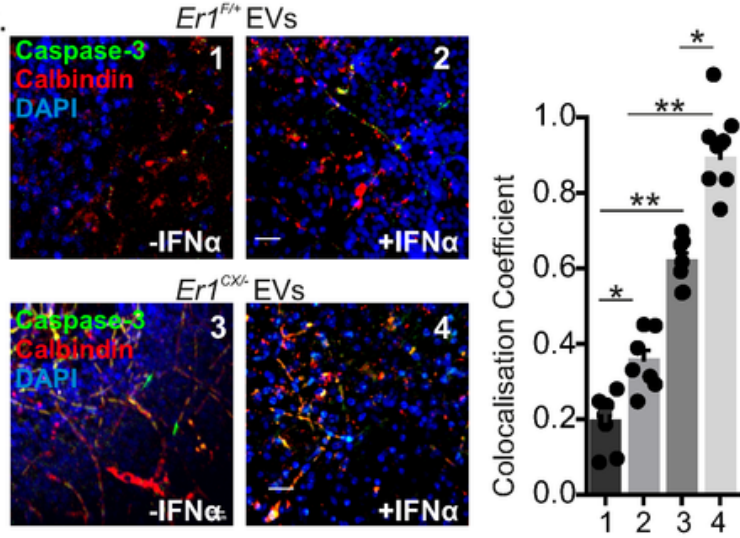

Gkirtzimanaki K. et al., Figure 6

Figure 6

Simultaneous 2-photon and 3-photon excited fluorescence microscopy images of Er1F/+ acute brain slices. The Er1F/+ acute brain slices are cultured in the presence of Er1F/+ and Er1CX/- EVs with (+) or without (-) rIFNa as indicated and stained for (A). PKH68TM (green) (pre-labelled EVs), Calbindin (red) and DAPI where the graph depicts the co-localization co-efficient between PKH-67 and Calbindin $(n=7)$ (B). PicoGreenTM (pre-labelled EV dsDNA), Calbindin (red) and DAPI where the graph depicts the co- 
localization co-efficient between PicoGreenTM and Calbindin ( $n=7)$ and (C). Caspase-3 (green), Calbindin (red) and DAPI where the graph depicts the co-localization co-efficient between Caspase-3 and Calbindin $(n=7)$. The white line is set at $10 \mu \mathrm{m}$ scale. Error bars indicate S.E.M. among $\mathrm{n} \geq 3$ replicates. The asterisk “*” indicates a p-value $\leq 0.05$, two-tailed Student's t-test.

A.

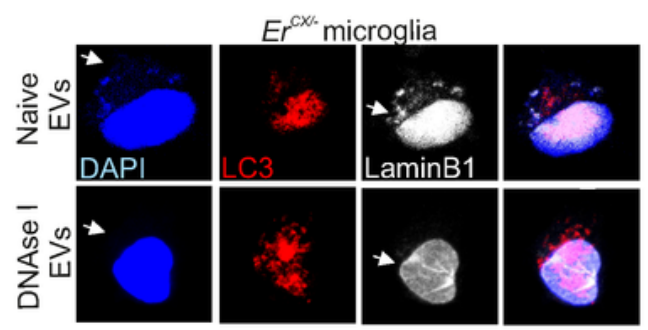

C.

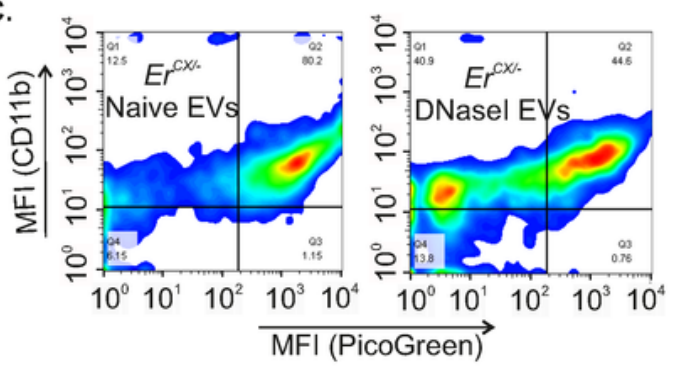

E.

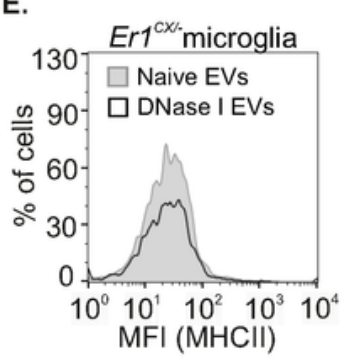

B.

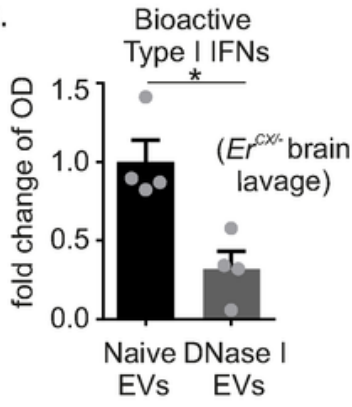

D.

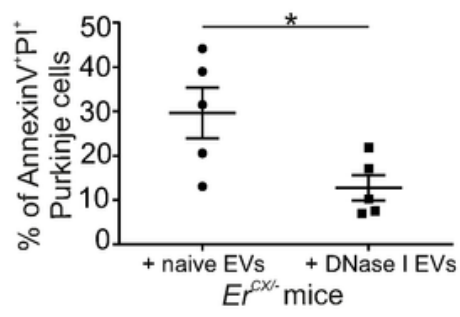

F.
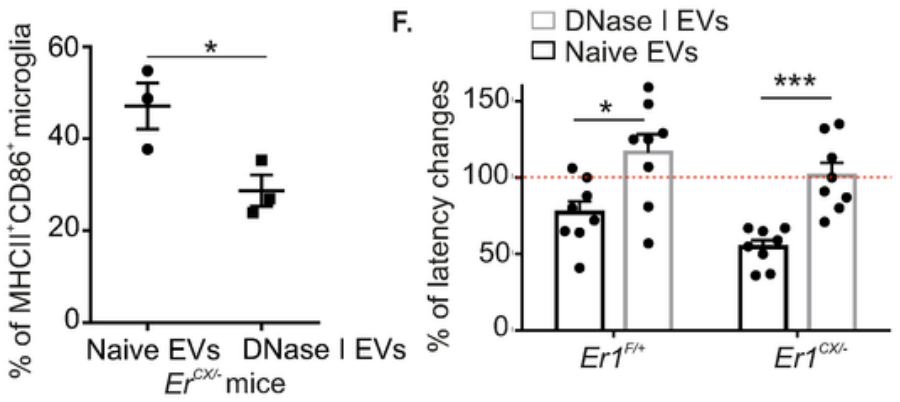

G.
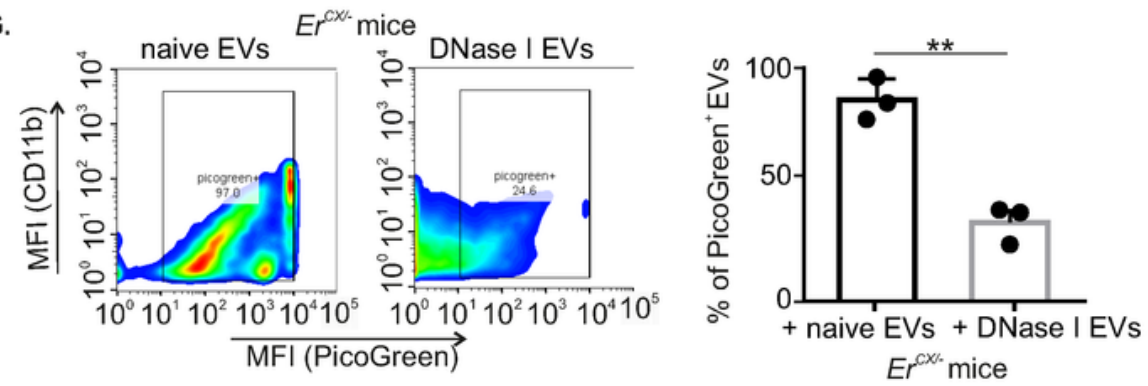

H.
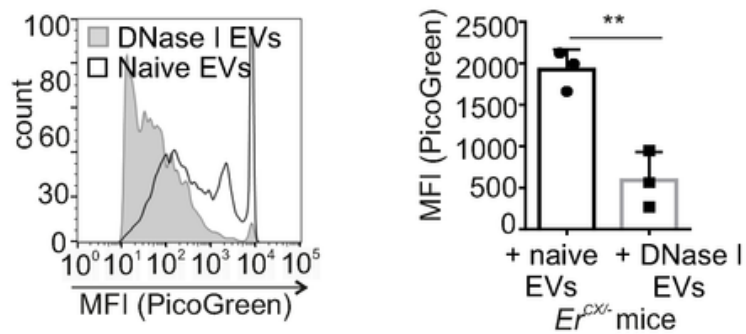

Gkirtzimanaki K. et al., Figure 7

Figure 7 
Er1CX/- microglia-derived EVs preferentially target IFNa-responding Purkinje cells leading to apoptosis. (A). Immunofluorescence of LC3 (red), Lamin B1 (white) and intensified DAPI on freshly isolated microglia cells derived from Er1F/+ and Er1CX/- brains, cultured in the presence of DNase l-loaded or empty (naïve) EVs. (B). Type I IFN bioactivity in the lavage of Er1CX/- brains injected intranasally with DNase I-loaded or naive EVs (30 Units of DNase I/administration, 12 intranasal instillations, once every 3 days) $(n=4)(C)$. FACS analysis of purified, PicoGreenTM -labelled EVs from Er1CX/- brain lavages incubated with DNase I-loaded or naïve EVs $(n=4)$ to assess the exosome-to-exosome fusion. (D). FACS analysis of freshly isolated cerebella from Er1CX/- brains treated with DNase l-loaded or naive EVs stained for Calbindin, Annexin and PI (as indicated). (E). FACS analysis of freshly isolated brain single cell suspensions stained for CD11b, MHCII and CD86. The graph depict the percentage $\%$ of

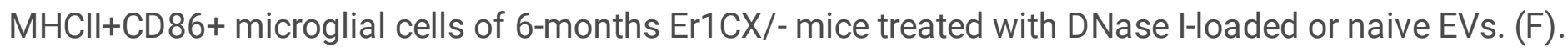
Graph depicting the latency ratios during Rotarod Assay (seconds on the rod before treatment/ seconds on the rod after treatment) of Er1Cx/- and littermate animals treated with DNase l-loaded or naïve EVs (no of mice / group=3; No of experiments=3). (G). FACS analysis of purified EVs from Er1F/+ and Er1CX/brain lavages of mice treated with DNase l-loaded and naive EVs stained for CD11b and PicoGreenTM. Representative plots depicting the elimination of dsDNA moieties upon in vivo DNase I administration. The graph depicts the percentage (\%) of PicoGreenTM + EVs. Immunofluorescence of MAC1/CD11b (green), Lamin B1 (red) and intensified DAPI on freshly isolated brain single cell suspensions of Er1F/+ and Er1CX/- mice treated with DNasel-loaded or naive EVs. The white line is set at $5 \mu \mathrm{m}$ scale. Error bars indicate S.E.M. among $n \geq 3$ replicates. The asterisk " $*$ " indicates a p-value $\leq 0.05$, two-tailed Student's ttest.

\section{Supplementary Files}

This is a list of supplementary files associated with this preprint. Click to download.

- Gkirtzimanakietal.Supplementalinformation.docx

- SupplementaryVideoFile1.mp4

- SupplementaryVideoFile2.mp4

- Figures1.pdf

- Figures2.pdf

- Figures3.pdf

- FigureS4.pdf

- FigureS5.pdf

- FigureS6.pdf

- Figures7.pdf

- nrreportingsummary20211129T101443.437.pdf 